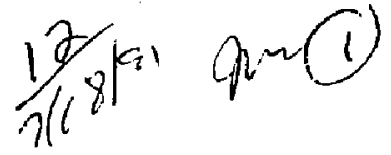

UCID-21607

\title{
PERFORMANCE IMPLICATIONS OF WASTE PACKAGE EMPLACEMENT ORIENTATION
}

\author{
Dale G. Wilder
}

Manuscript Date: Marcl 14, 1990

Publication Date: May 1991

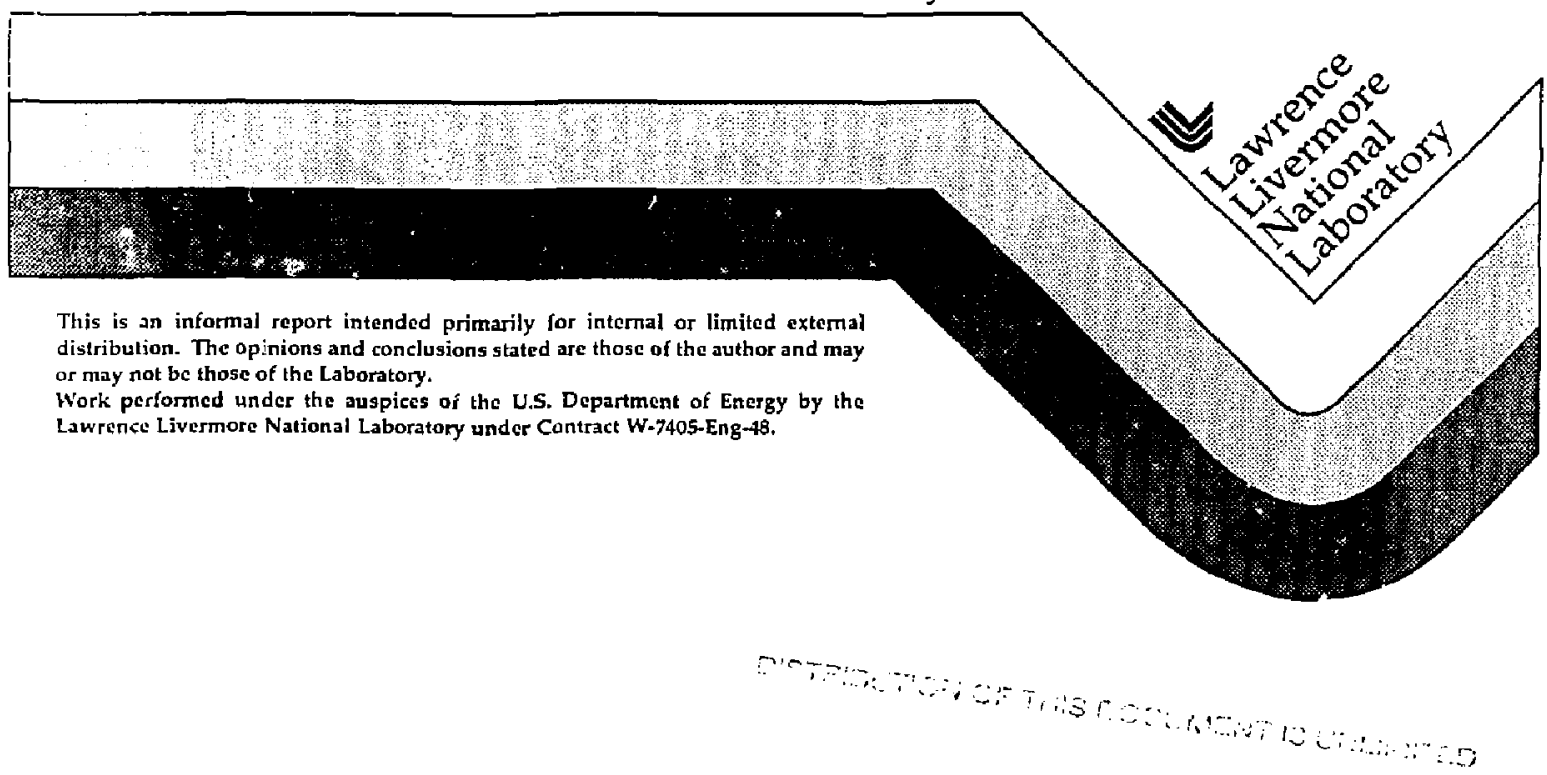




\section{DISCLAIMFR}

This dacume'nt was prepared as an account of work sponsored by an agency of the Lintex States Governmemt. Vieitluer the Linted States Government nor the Liniversity of California nor any of them employers, nakes any warranty. express or implaed. or assumes any legal liability or responsibility for the dccuracy. completeness, or useruiness si any

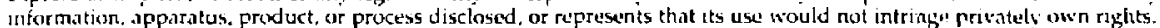
Refurence hercin to anv specific commercial products, process, wr service by trade name, trademarn, manufacturer, or otherwise, does not necessarily constitute or imply its endorsement, reconsmendation, or facoring by th. Linted States

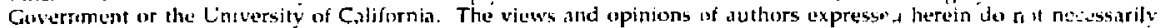
stale of rel!ect thuse of the Liniled States Government or the Liniversity of Cal cirnts, and shall nol be used for advertasing or product endorsenient purpisses.

This repurt has oeen reproduce: I difectly from the b st arialable copy

A culable to DOE and DQE contraturs frum the Office of Seitertific and Technicad infermation P'O. Bux h2, Oak Ridge. TX Fik?

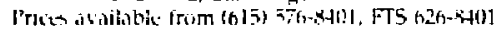

A turlable to the public from the Viaturnai Techusal Intormatum Service

LS Depurtment of Cumnore 52k5 l'ort Ruyal Ru.

Springhiede. vis z?|G| 
Foreword:

This paper was prepared to identiiy those hydrologic processes that are influenced by the emplacement orientation, and that (in the view of the author) impact long term performance of the Waste Package. The intention of the paper was not to provide detailed or quantitative analyses relative to the issues but rather to identify the processes for which quantitative studies or analyses need to be performed. Thus, many of the ideas are conceptual but are discussed in the paper because they are not contained in other project documents.

At the time that the report was prepared, vertical emplacement was the reference orientation but final orientation was not selected. Subsequent to the preparation of this report, the Yucca Mountain Project completed an emplacement orientation selection-decision analysis process that reaffirmed vertical emplacement as the reference case and directed all studies to be focused on the vertical case without precluding horizontal emplacement. This decision was not made on the basis of analyses of the technical issues defined in this paper. The technical issues identiffed in this paper are yet to be addressed in $a$ rigorous fashion. Furthermore, since there are no studies proposed to address all of the technical issues raised in this report, it is the judgment of the author that the report serves a necessary function in identifying the processes that need quantitative studies or analyses, although the purpose of the ieport is somewhat changed. 


\title{
Performance Implications of Waste Package Emplacement Orientation
}

\author{
Dale G. Wilder \\ Lawrence Livermore National Laboratory \\ Livermore, CA 94550
}

\begin{abstract}
Emplacement borehole orientation directly impacts many aspects of the Engineered Barrier Systern (EBS) and interactions with the near field environment. This paper considers the impacts of orientation on the hydrologic portion of the environment and its interactions with the EBS. The hydro!ogic environment is considered from a conceptual standpoint, the numerical analyses are left for subsequent work. As reported in this paper, several aspects of the hydrological environment are more favorable for long term performance of vertically oriented rather than horizontally oriented Waste Packages.
\end{abstract}

\section{INTRODUCTION}

The orientation of emplacement boreholes (either vertical or horizontal) directly impacts many aspects of studies and design; being considered by the Yucea Mountain Project. Eariy emplacement orientation selection would prevent much duplication in the field testing effort. The purpose of this paper is to identify the potential impacts that emplacement orientation has on the Waste Package (WP) containment and release rate performance. The basis of the concern addressed here is contact of water with the WP container.

The performance allocation and WP strategy rely (in part) on limiting the amouni of water that can contact the containers, as well as limiting changes in water quality (DOE, 1988). The Waste Package performance strategy, as discussed in the SCP, relies heavily on the performance of the containers to provide substantially complete containment for a period of time extending 1000 years after repository closure. During the first 100 years, waste package performance is allocated entirely to maintaining container integrity. During the period from 100 to 1000 years, performance is based on most of the containers maintaining their integrity, with failure occurring gradually with time. It is only after 1000 years that performance is allocated to controlled releases that result from gradual leaching of the waste form by aquecus solutions. The most likely failure mechanisms for the candidate container materials involve interactions between the container materials and water. Thus, by limiting the contact of water witt: the containers, the long-term performance of the WP can be better assured.

Current performance strategies rely on limiting water entry onto WPs for at least 300 years $(\mathrm{SCP}$, 1988). The temperatures of waste during the first 100 years are expected to be sufficient to prevent water entry in to the boreholes. Therefore, water contact with waste packages is an issue nainly during the 100 to 1000 year time period when gradual degradation of containers is relied on. The amount of water contacting the containers will influence the rate of degradation of the containers. Therefore, the tocus ni this paper is the irapact of emplacement orientation on water flow into WP boreholes principally from 100 to 1000 years 2 iter emplacement.

Current understanding of the hydrologic and geologic conditions within the repository horizon is incomplete and, therefore, performance analyses must consider a range of conditions. The rock-mass is unsaturated, although the degree of saturation is expected to have a mean value of about $65 \%$. Water flux is expected to be low, although actual values are also unknown at this time. There are several possibilities, including vertical flux resulting frorn upward vapor transport from the saturated zone (Montazer and Wilson, 1984). It is also not clear at this time what percentage of any water that may move 
through the rock-mass will flow thruugh the fractures. The amount of water that flows in fractures is a function not only of matrix properties but also of the amount of water available and the aperture of the fractures.

The extent to which water can enter a borehole from matrix flow depends on the balance between suction or matrix potential and the gravity gradients. The balance between suction and gravity for horizontal boreholes is illustrated by Fig. 1 . Inflow will occur if the component of the gravity gradient normal to the borehole $(\rho g \cos \theta)$ exceeds the matric potential. The potential for inflow can be evaluated along any radial direction since the velocity of the flow will be less than zero (sign convention is positive along the ratial distance a way from the borehole) whenever any inflow occurs. The conditionis under which intlow will occur (considering the upper portion of the borehole where gravity gradients act towards the hole) can be written as:

$$
P_{w}-\rho_{w g} \cos \theta<0
$$

Thus, for $P_{w}>0$ (matric potential exists) water can flow from pores into boreholes or apenings only when $\cos \theta>0$ ior $-90^{\circ}<\theta<90^{\circ}$ ). Therefore, for vertically oriented boreholes, as long as the matrix is unsaturated, pore water cannot enter the boreholes because of the strong matric potential. Only through fracture flow or some alteration of hydiologic properties, i.e., secondary mineralization which might concentrate pore fluids in the fractures or boreholes, can water enter the vertical boreholes themseives. Flow from the matrix into the openings does not simply depend on geometry, and the simplified equation shown is not sufficient to determine whether flow into a borehole will occur, rather what geometries are necessary for that flow to occur. The more general form of the equation

$$
\left.\left(\frac{\rho_{w} \cos \theta}{-\frac{\delta P_{c g w}}{\delta S_{w}}}\right)\right|_{d=r}>\left.\frac{\delta S_{w}}{\delta d}\right|_{d=r}
$$

(where $P_{\text {cgw }}$ is capillary (matric) potential of the water phase of gas-water pore fluid and is a function of saturation and $S_{w}$ is saturation) must be used to evaluate the potential for pore-fluids to enter the

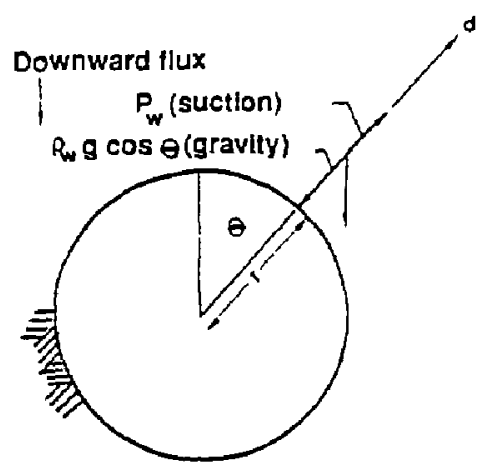

Figure 1. Inflow into horizontal borehole under unsaturated conditions. 
boreholes. However, information is lacking to evaluate $\delta \mathrm{P}_{\mathrm{egw}} / \delta \mathrm{S}_{\mathrm{w}}$ and $\delta \mathrm{S}_{\mathrm{w}} / \delta \mathrm{d}$ and, therefore, the more simplified s:quation was used in this evaluation.

Although other aspects, specifically cherristry and WP design options, could change the impacts of the hydrologic response and are closely reiated to the hydrologic response, they are not discussed in detail in this paper. Where the relationship between these issues and hydrology is germane, they are discussed brieIy. It is not the iniention of this paper to evaluate all possible parameters that will be considered in making a decision of emplacement orientation; rather, the intent of this paper is to identify (conceptually) the influence of emplacement orientation on hydrologic impacts on WP perfor:: ance. Detailed numerical analyses of the hydrologic processes are left to future work.

As previously stated, matrix tiow under expected limited flux conditions is not expected to adversely impact the WPs. Only the larger flow which could be postulated for fractures under extreme conditions will impact the WPs. To understand the relationship between WP performance and emplacement orientation, one must first understand the relationship between hydrology and orientation. This will be influensed by the iracture system.

Our understanding of fracture networks at Yucca Mountain is incomplete; however, fracture sets within the Topopah Spring unit (the repository target horizor) are expected to be preciominately vertical with dominantly $\mathrm{N} 2^{\circ} \mathrm{W}$ and $\mathrm{N} 28^{\circ} \mathrm{W}$ strikes (Scott and Castellanos, 1984). The predominately vertical tip and north to northwest strike rracture orientations are generally consistent with the fracture syster.? mapped by Barton at pavement outcroppings (see Fig. 2).

Fracture spacing cannot be well determined from the vertical cores. Scott and Castellanos (1984), aiter correcting their data for orientation and geometric bias, reported 42 fractures $/ \mathrm{m}^{3}$ for the Topopah Spring member. Since more than $75 \%$ of the fractures had inclinations within $10 \%$ of vertical, this equates to more than 7 fractures per foot horizontally. If dominant fracture orientations (strike) are considered, the fracture spacing would be even less. Because ot the bias introduced in the correction applied by Scot: and Castellanos, a fracture spacing of 1 foot will be assumed for purposes of this report. (For discussion of correction bias, see Yow and Wilder, 1983, and Yow, 1985).

\section{DISCUSSION}

As previously indicated, as long as the repository horizon rock remains unsaturated, water canriot leave the pores, where it will be under significant negative (suction) pressures, and enter the emplacement boreholes. This assumes that an air gap is maintained so that there will be a capillary barrier to effectively inhibit flow from the pores into the borehole. An analysis of the matric potentials and the most likely environmental conditions for a horizontal emplacement as discussed by Nitao (1988) indicates the effectiveness of the capillary barrier. Therefore, under expected saturation conditions, there are only two likely ways for liquid water to contact the WP container. The first is through borehole failures that bring rock into contact with ihe container, thereby providing a wick for the water to contact the WP. The second is by flow in fractures where capillary forces presumably will be less than in the matrix. During heavy recharge events, if the fractures become filled with water at a rate that exceeds the rate of imbibition from fractures into the adjoining matrix, it is possible for the water to flow through fractures. Under these conditions, it may be possible for water to enter those WP emplacement boreholes that are intersected by fractures. A third, but more remote, possibility is for vapor to be driven from rock surrounding a hot waste package(s) into the emplacement hole of a cooler WP where it sould condense on the WP container surface, providing the temperature of that WP was below the dew point temperature. This is considered a possibility only for a few containers, probably at the boundary of the repository, and could only occur when overall temperatures dropped considerably, at which time most of the water nould have been driven away from the WPs. 


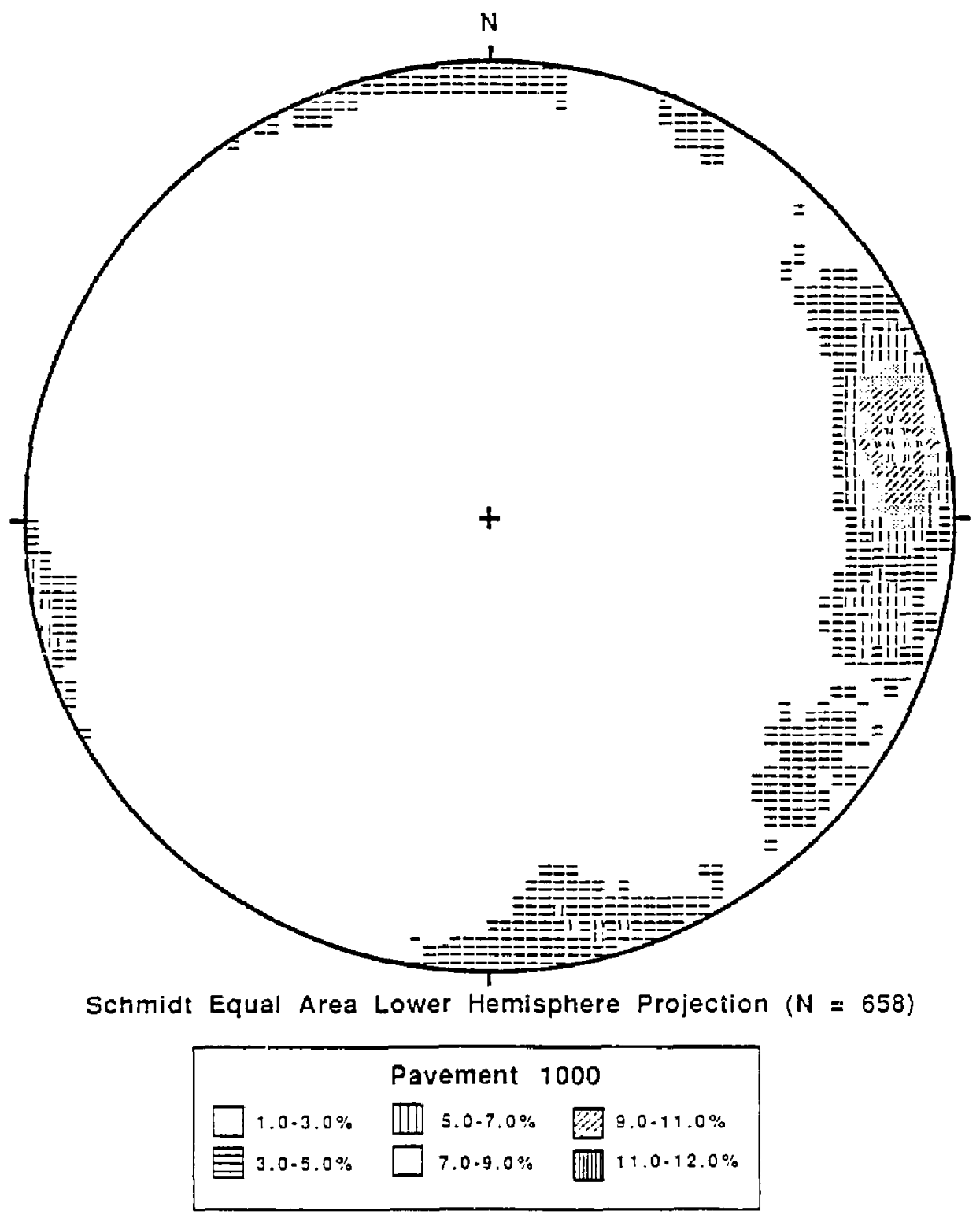

Figure 2. Fracture orientations from pavement mapping (from Yow). 


\section{Water Entry onto Waste Packages under Fracture Flow Conditions}

Given a fracture spacing of one foot, a 24 to 30 -inch-diameter vertical borehole would likely intersect a minimum of 2 to 3 fractures that were parallel to the hole centerline. In a vertical fracture, water will tend to flow vertically downward in the fracture itself (parallel to the borehole) and not into the borehole, unless the fracture intersected the borehole at an angle. The flow paths around the drift are illustrated in Fig. 3. (This argument neglects any water which bypasses seals and flows directly into the borehole from the drift, or that small portion which would flow laterally by capillary-induced spreading or other dispersive processes rather than gravity.) Secondly, unless no fractures intersect the bottom of the borehole, or unless fractures heal or close, water in the borehole should drain freely through vertical fractures in the bottom of the borehole rather than accumulate in the borehole itself. Any water that enters the borehole will tend to flow along the borehole walls until it gets to the bottom of the hole, where it would drain out. Water flow into and out of the borehole is illustrated in Fig. 4. An underlying assumption is that the WP container itself does not torsch rock anywhere, including the bottom of the hole. The validity of this assumption depends on the design used; however, other design aspects that will be discussed later make this assumption less important.

For horizontal borehole orientations, the nurnber of fractures likely to be intersected will be approximat sly one per foot of borehole length. Therefore, horizontai orientation of boreholes would incrcase the number of fractures intersected by boreholes and thus increase the potential for water to contact WPs relative to vertical borehole configurations. While this increase will not likely be a linear relationship with number of fractures (Bawden, et al., 1980), there will be some increase in potential water inflow. Furthermore, the boreholes will cut the flow paths so that water flowing in the fractures will tend to drip into the boreholes and onto the WP containers. This is true even for low flow rates since water intercepted by the upper (nearly horizontal) segments of the borehole will tend to form pendular drops

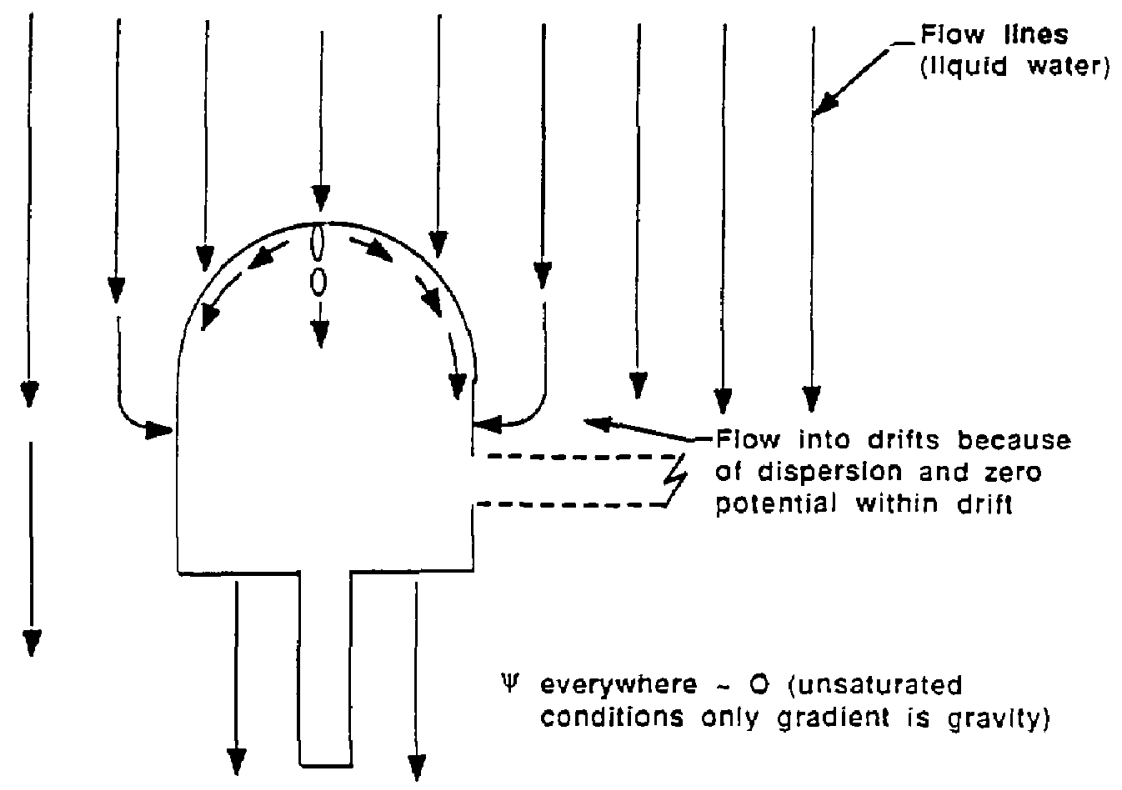

Figure 3. Cross-section of repository along fracture surface showing liquid flow within fracture. 


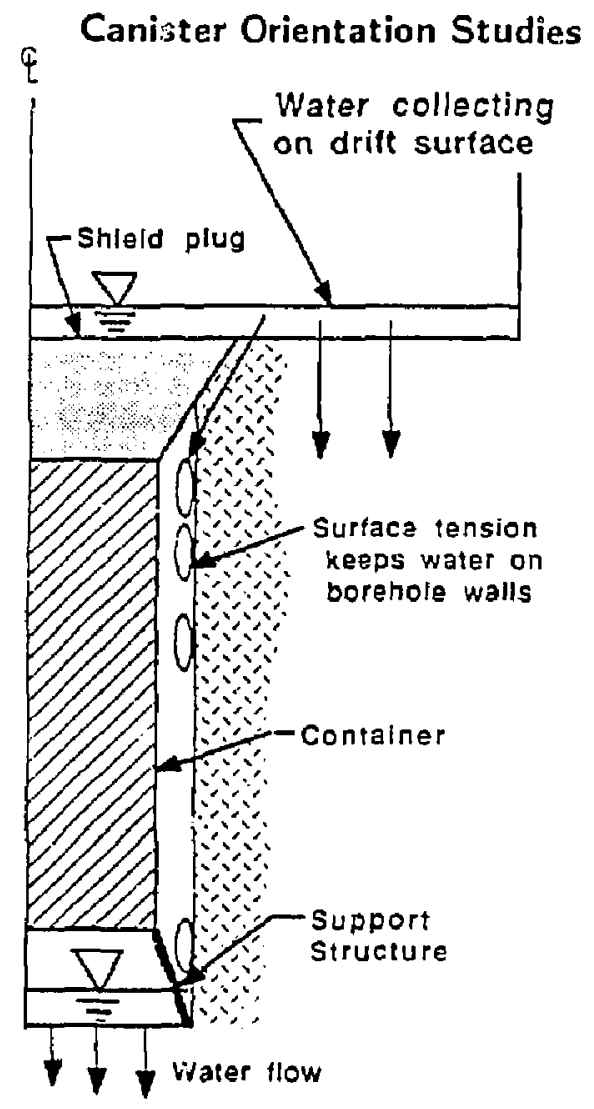

Figure 4. Cross-section of vertical emplacement borehole showing liquid flow within borehole.

until they become large enough to fall directiy onto the WP. Since current WP design is for WPs to be supported off the bottom of the boreholes (MicCright, et al., 1987), any water falling on the top (upward surface) of the WP (assuming WP temperatures are below the boiling poirt) will flow around at least a quarter of the WP circumference before it can fall back into the borehole. It is also likely that the water will flow around ine WP surface to the bottom of the WP and hang there until the drops become large enough to overcome the surface tension and fall to the lower perimeter of the borehole. These flow paths are illustrated in Fig. 5.

\section{Effects of Salt Disposition on Chemistry of Water Contacting Waste Packages}

When the package is hot, water will evaporate or boil from the rock near the WP or from the container surface, thus depositing salts either on the container or in the fractures near the WP. After the package co Is, any water that drips onto the container or flows through the fractures containing jeposited salts will dissolve those salts. The resulting water may be highly corrosive to the container. The extent to which the deposition and dissolving of salts is an important consideration depends on the 


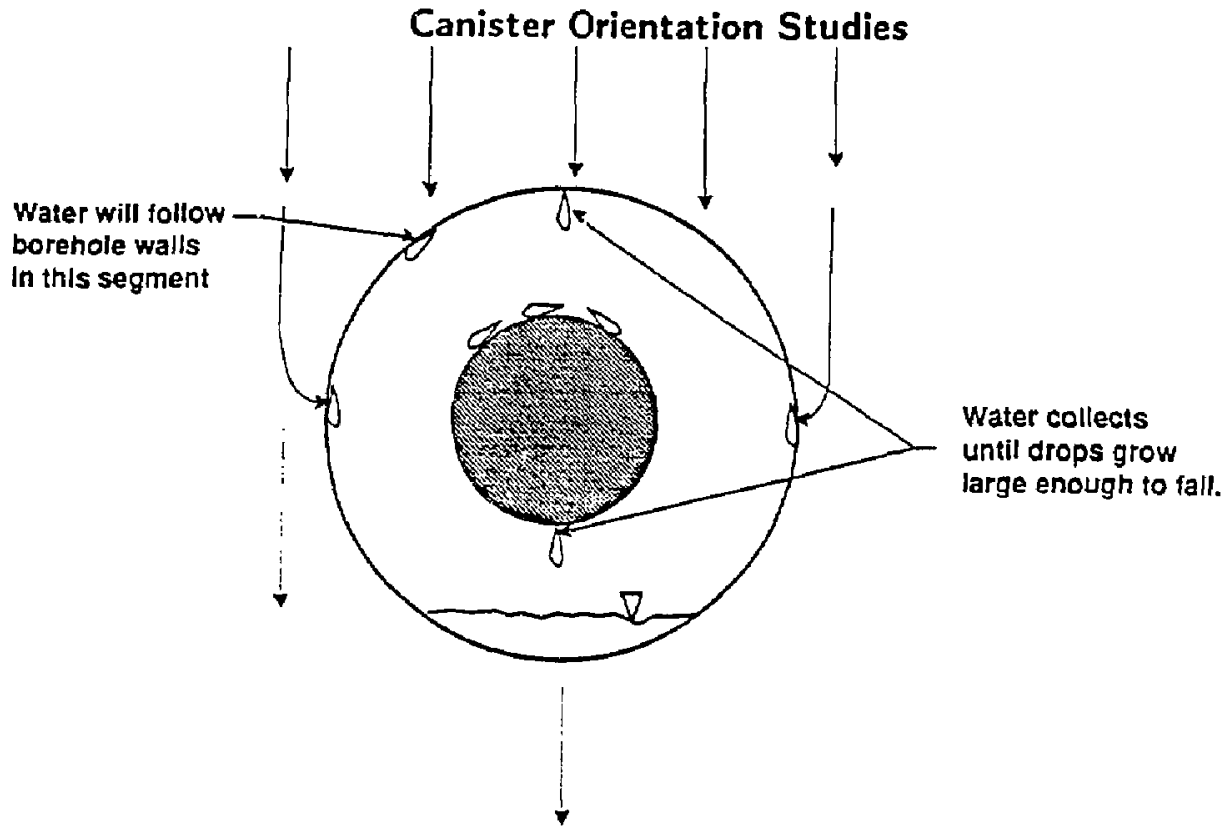

Figure 5. Cross-section showing flow of water along fracture surface intersecting horizontal emplacement borehole.

amount of reflux and repeated evaporation with accompanying salt deposition that takes place. Since groundwater at Yucca Mountain is very dilute, even after a cycle of concentration from deposition/ dissolution the total salt content (salinity) may be very low. This salt concentration is of more concern in the horizontal orientation since the amount of potential reflux is greater for the horizontal orientation, as will be discussed later.

\section{Increased Fracture Permeabi:ity Resulting from Waste Emplacement}

In addition to different flow into the boreholes for a horizontal vs vertical emplacement, the environment and thus long-term flow conditions will be altered in a different manner for the horizontal and verticat orientations. During heating, the rock will undergo deformations which will cause deformations of the fractures within the rock-mass. The fracture response to the deformations will include both normal and shear displacements. Research has docuinented that shear displacement causes greater permanent changes in aperture and permeability (which usually increases unless extreme shearing takes place that crushes all asperities) of fractures than do nomal displacements (Banctis, et al., 1983, Barton, et al., 1985, and Wilder, 1987), although both modes exhibit hysteresis. This has implications for the long-term performance of the WP as outlined below.

It is urilikely that water (other than vapor) will enter the boreholes during the period when the waste is hot enough to keep rock temperatures above the boiling point of water. During this time, liquid water will be vaporized and driven away from the boreholes. When the rock cools, fractures that experienced shearing are likely to have greater hydraulic conductivity than they had prior to thermal deformations. The effects of shear displacements are a function of scale as well as orientation. Hoop stresses that may develop around boreholes will modify fracture deformation responses immediately around the 
boreholes; however, the extent of these stresses will be limited to the rock in the immediate vicinity of the boreholes. This is in contrast to repository scale stresses that result from waste emplacement, wirich extend considerable distances from the boreholes into the large scale fow system. Borehole effects will modify the mpact of the repository scale effects but will probably not override them. Thus, while hoop stresses may tend to modify the amount of shear displacement (and thus increased permeability) in the immediate borehole or drift vicinity, the overall repository effects will impact the hydrologic regime of the repository (Wilder, 1987).

For vertical emplacement, normal ceformations along the vertical fractures will predominate, except directly above or below the WP (see $F_{i b} .6$ ). Therefore, once the rock-mass cools there will be minimal change in fracture conductivity except for those fractures in the regions between the WP and drifts and immediately below the WPs where shear displacements may increase permeability. Increased permeability below WPs will prevent water contact with WPs since it will allow better drainage of the borehriles. Although water that may collect in the drifts could enter the more permeable fractures above the WPs, drift designs provide drainage away from the area of waste emplacement. This drainage should divert part or all of the water that might enrer the drifts away from the boreholes. Furthermore, the drifts themselves may serve to shed water to the pillar area, as will be discussed later, and the backfill within drifts (if used) will be more permeable than the rock matrix. This will provide a type of capillary barrier to matrix flow, depending on the pore sizes that result from backfilling, although the porous backfill may also serve to wick water from the rock matrix into the backfill. WP emplacement design (as discussed later) can ameliorate the flow conditions into the borehole. This is more easily accomplished for the vertical emplacement than for horizontal emplacement. The modifications to the flow are depicted by Fig. 7 .

Fractures will also have significant shear deformations resulting from different magnitudes of deformation with distances from the heat sources. As the volume of rock-mass that is heated increases, the differential deformations will occur progressively further away from the $W_{2}$. The differential deformations will cause shear displacements of the predominately vertical fractures in different regions of the rock-mass depending on time and fracture orientistion. Once again, when the rock-mass cools, the shear deformations will likely not be entirely recovered (Bandis, et al., 1983. Barton, et al., 1985, and Wilder 1987). Neglecting fracture healing, if downward flux is sufficient for fracture flow to occur, the permanent deformations will result in a potential for greater amounts of water to enter the boreholes than prior to waste emplacement. The impact of shear displacements is expected to be greater in the horizontal emplacement case because most of the fractures will cross the borehole and allow for

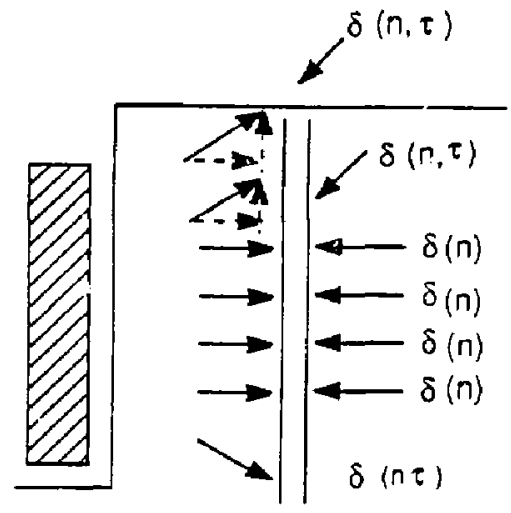

Figure 6. Verical cross-section showing fracture deformations. 

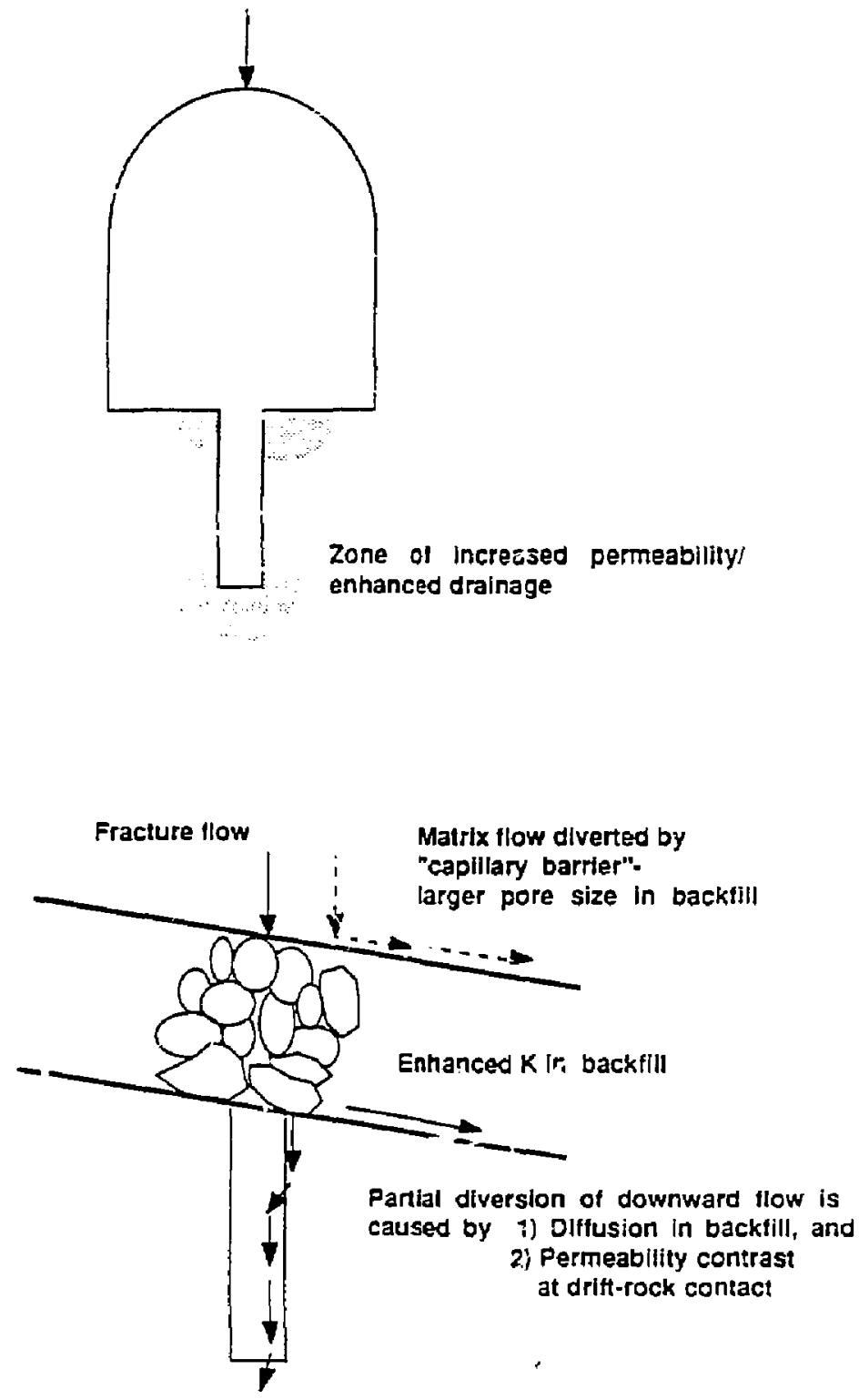

Enhanced drainage (Increased permeabillty)

Figure 7. Impact of increased fracture permeability and d:ift backfill, vertical orientation. 
differential movement on successive fractures to relieve the shear deformations of the rock-mass (see Fig. 8). In the vertical orientation the shear will occur along portions of a single (or few) fractures, but fractures that are striking in a tangential direction will experience normal deformations. The increased fracture pormeability : rill be greatest in the area of the WP (see Fig. 9).

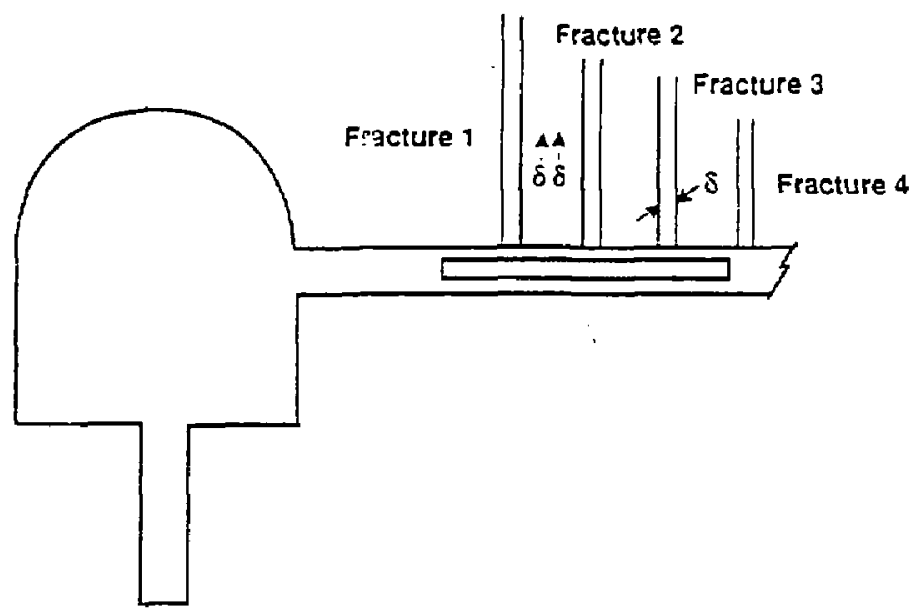

\section{Cross.Sectlon}

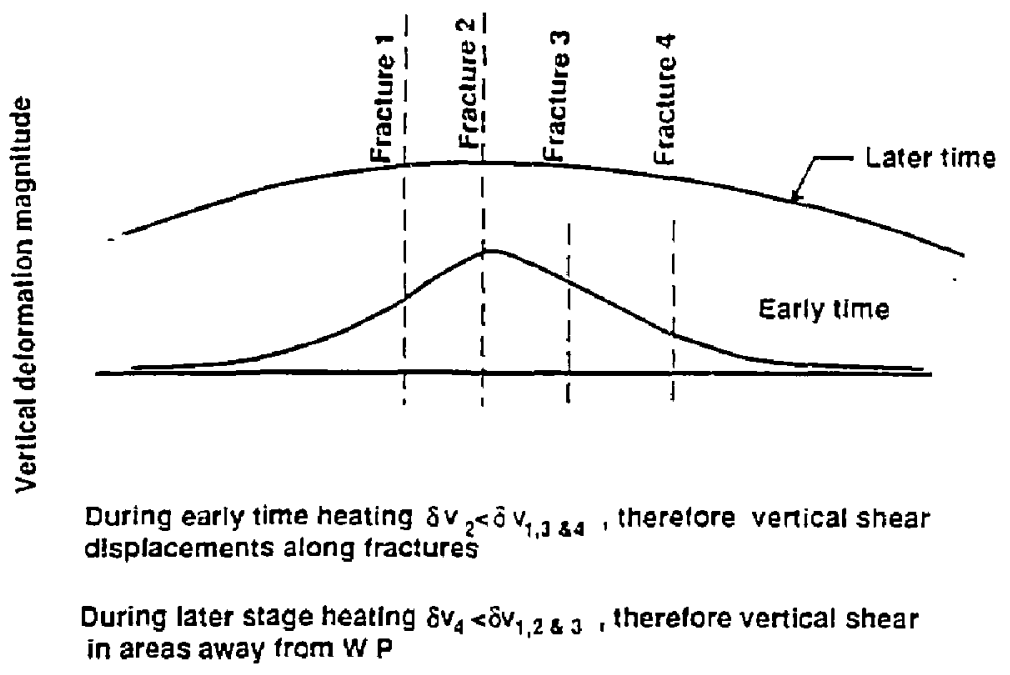

Figure 8. Deformations as function of position along emplacement hole. 


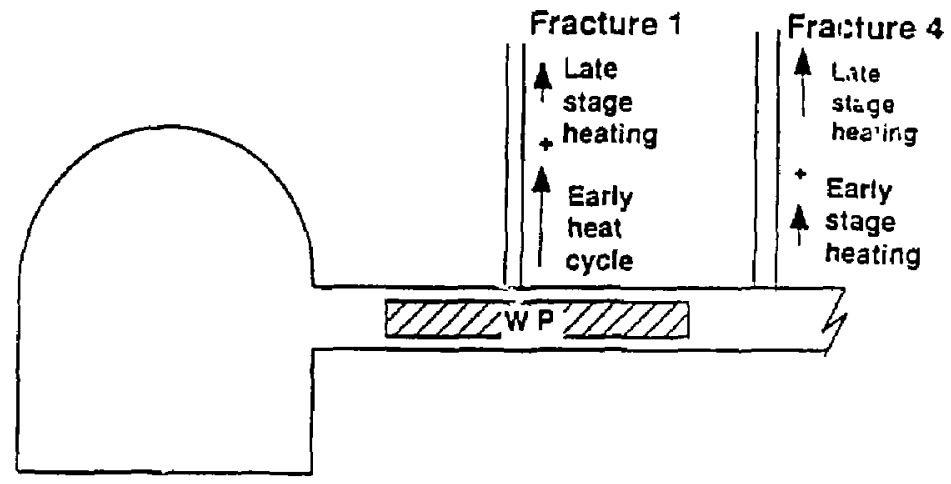

Figure 9. Relative shear displacements due to heating.

\section{Fracture Permeability Increase from Repository Excavation}

Numicrical anaivses of the stresses that result from excavation and waste emplacement were performed for both hurizontal and vertical emplacement modes (St. John, 1987). The analyses used the drift configurations that were considered appropriate for the two emplacement orientations (although shorter borehole lengths, for the horizonta! case, than considered in this paper are now veing considered). The results are summarizcu in Fig. 10. As is apparent for both emplacement configurations, the orientation of the maximum principal stress vec.ors in the pillars between panels change from vertical before waste emplacement to nearly horizontal after closure ( 100 years post-emplacement). The changes ifi stress orientation beneath the drifts themselves are less pronounced, almost non-existent. Direct analyses of resulting deformations or strains are not available; however, a reasonable assumption can be made that the largest deformations of the rock and fractures will occur in the direction of the maximum pri:apal stress change orientations. Where these orientations are oblique to the fractures, shear deformations will result; normal deformations will predominate otherwise. Figure 11 summarizes the regions of the intermediate scale rock-mass surrounding the WPs where shear deformations will occur along the predominantly vertical fractures.

\section{Construction and Emplacement Impacts on Quantity of Water Potentially Contacting WPs}

In addition to the above factors, the quantity of water available to enter the WP must be considered Two issues or factors related to the amount of water available will be considered in this section. First, potential for net removal of water from the system, which obviously would decrease the volunic of water that could potentially contact the WPs; and, second, the location of remaining water and therefore potential to migrate into WP boreholes. A third factor which may be an importanic consideration is the creation of preferential flow paths for existing flux resulting from increases in saturation. These flux flow paths could be either matrix flow wherein flux can move more rapidly since only smail additional volumes of water would be required to nearly saturate the matrix or fracture flow wherein flix could flow in fractures since matric potential would be decreased by increased saturation. While the third issue may have a significant impact on WP performance there is not sufficient information to properly evaluate it at this time. Therefore, this issue is not discussed in further detail. 
a)

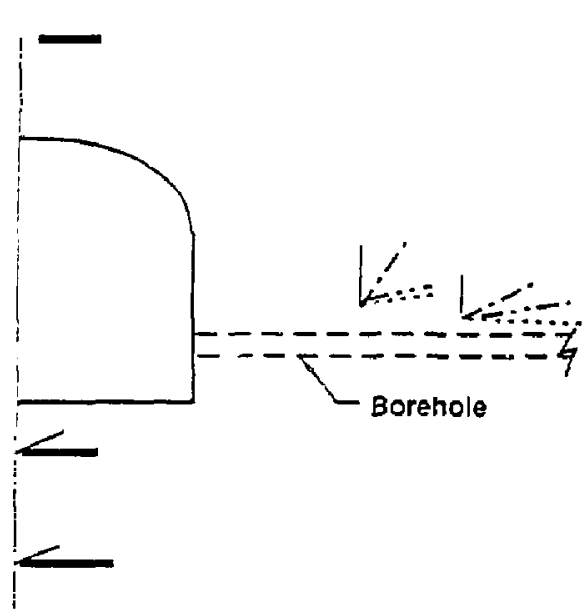

Horizontal emplacement b)

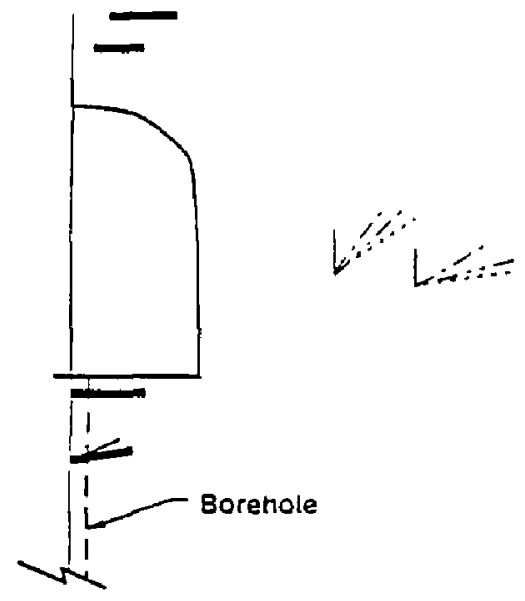

Vertical emplacement

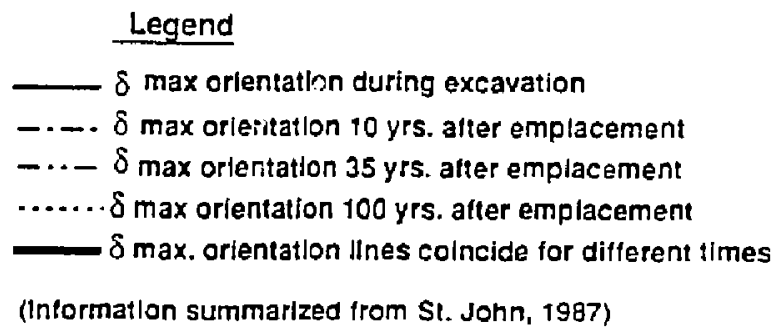

Figure 10. Orientation of maximum princjpal stress.

\section{Effects of Dry-Out and Steam Condensation on Potential Water Contact with WPs}

Water that is removed during heating will flow as vapor principally along fractures (Daily, et al., 1987 ) to cooler regions where the water vapor will condense. Presumably any water removed from the dried out zone would need to be replaced in the rock-mass matrix betore water could flow through the dried out zone and into the emplacement boreholes. Removal of condensate would delay the time when renydration was completed to the point that water could enter WP boreholes.

The condensate might be imbibed into the rock matrix in the condensation area, where it would remain until the degree of saturation increased sufficiently to allow either fracture or matrix fow. Since the matric potential is a function of the degree of saturation, if the degree of saturation is raised suificiently, a downward flux (or increase therein) will be created and imbibed condensate cor an equivalent volume of percolating water) could migrate downward and away from WP borehole areas. Furthermore, if the volume of condensate is sufficient to exceed the imbibition rate, water will flow in the fractures rather than be imbibed into the matrix. 


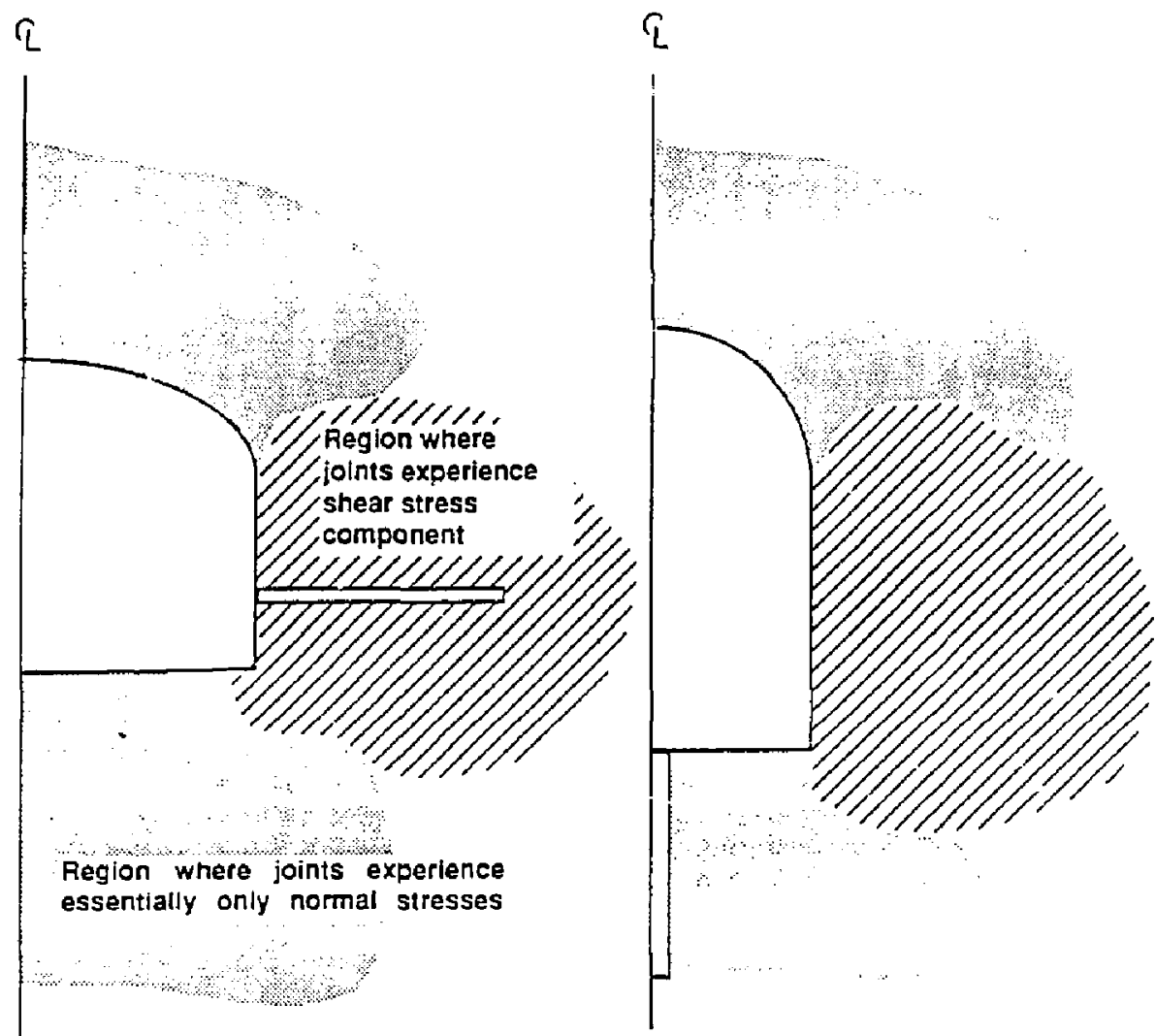

Horizontal Emplacement Vertical Emplacement

Figure 11. Regions of rock undergoing shear displacements (based on maximum principal stress orientations of St. John (1987), as well as analyses within this report) as a result of waste mplacement.

Gravity-driven water migration through either pores or fractures will occur at saturations less than $100 \%$. The degree of saturation in the undisturbed condition is expected to be approximately $65 \%$. Thus. unless the volume of rock where condensation occurs is considerably larger than the volume of rock that is dried-out, there should be a net downward migration of a significant portion of the water removed from the dried-out zone. If condensation takes place in a smaller volume of rock than was dried-out, an even greater percentage of the water from the dried-out zone will migrate away from the dried-out zone, since the degree of saturation would increase more rapidly to the point where down ward flow took place, after which all subsequent condensation would be able to migrate.

Further, as shown by Montazer and Wilson (1984), the "dominance of fracture flow starts at a lesser degree of saturation under wetting than under draining conditions," and this phenomenon is most pronounced in rocks with low matrix permeabilities. Condensation is equivalent to wetting, so fracture flow 
would occur at lower sdturation in the regions of condensation than would occur under uniform saturation conditions.

Regardless of whether the water from condensation remains in the matrix or flows in fractures, the ultimate issue is how much of the water removed during dryout remains in the system in a position where it can move back to the WP environment once the rock-mass cools. Figures 12 and 13 depict the moisture/vapor flow conditions based on location of the boiling point isotherm with time, as predicted by Hertel and Petney (1989). As can be observed in Fig. 12b, water vapor driven from the near-field environment during the first few years af́ter emplacement for vertical emplacemet will either escape into the drifts, or condense as liquid water in the rock beyond the boiling point isotherm. Because much of the vapor from the rock-mass above the WP can preftrentially escape into the drift very little condensation will occur in rock above the top of the WP. The increased saturation that results from the condensation will increase the potential for fracture ilow and gravity drainage as well as imbibition into rock with lower saturation. This will effectively remove most of the water from the $10 \mathrm{~m}$ of rock surrounding the WTs from locations where it could potentially return to the WT environment. After 20 years the boiling point isothet ms from adjoining drifts will coalesce (see Fig. 12c) so that moisture removed will tend to condense in equal amounts above and below the WP but the condensation will be greatest at the pillar mid-planes. Furthermore, condensation above the WP emplacement horizon will be restricted from
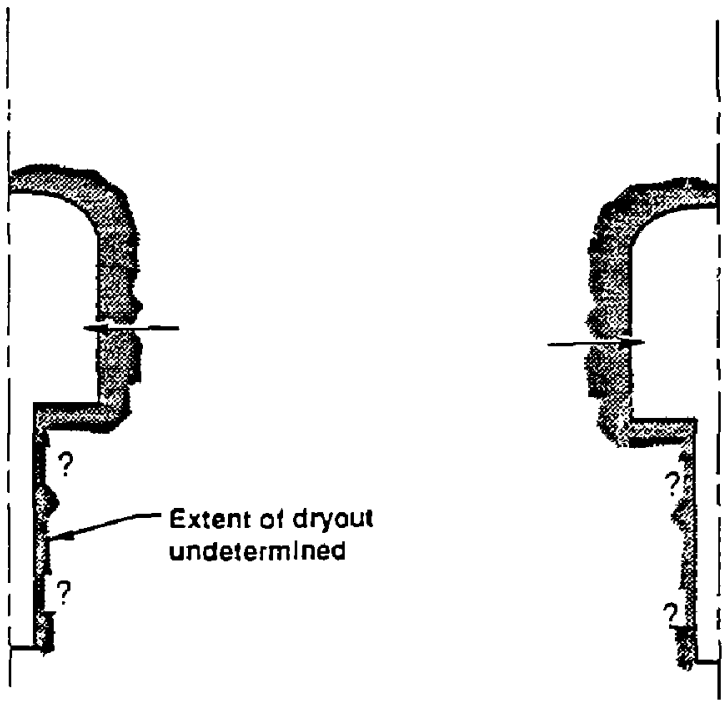

Legend

----- Water removal by ventllation during excavation

Water removed during early thermal cycle

Water removed atter closure

$\triangle \backslash \mathrm{Molsture}$ increased above ambient conditlons

Figure 12a. Construction and pre-emplacement. 


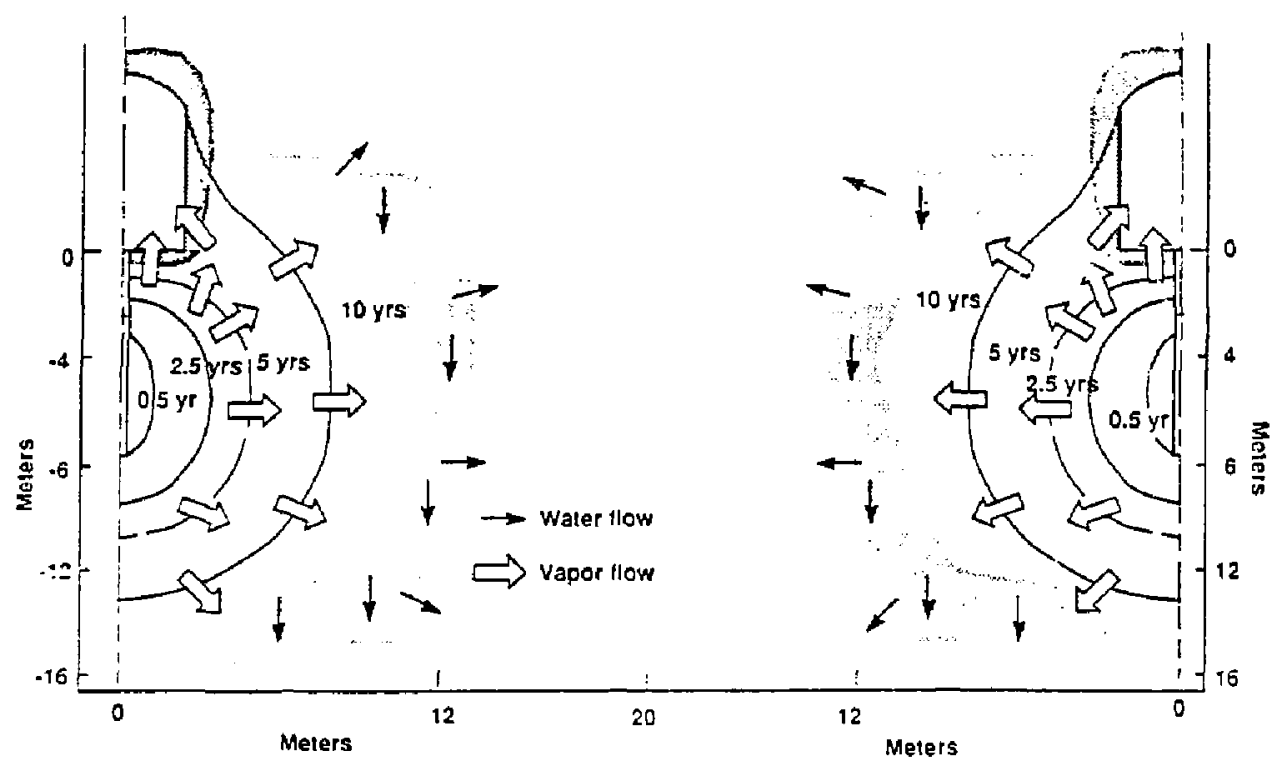

Figure 12b. Ten years post-emplacement modified from Hertel and Petney (1989).

downward migration by the hoiling point isotherm which will create a perched type water rondition above the WP horizon. In contrast, the condensation below the WP horizon will be unrestricted in downward inigration. This will result in a more uniform moisture distribution below the WPs and pillar areas, but with potentially less water remaining in this portion of the rock-mass.

After 100 years the boiling point isotherms are essentially flat lying with respect to the WP so that moisture removal and collection will tend to be uniform from that point on. However, less moisture will condense above the WP than the pillar mid-plane for two reasons. First, the moisture that was in the rock-mass of the drift would be removed during excavation and therefore would not be driven oft during early thermal pulse and secondly during the early (first 10 years) thermal rock cycle much of the water removed from immediately surrounding WPs would have either escaped into the drifts or condensed and migrated to elevations below the WPs. An analysis of the amount of moisture per unit area that would be condensed during the first 100 years of drying was made assuming that all water removed above the WP center migrated vertically upward and was deposited in a position directly above the rock-mass from which it was driven. This analysis assumed $65 \%$ saturation and $15 \%$ porosity and was strictly "back-ofthe-envelop" so that it should only be considered as a first approximation. As can be seen on Fig. 14 approximately $1.7 \mathrm{~m}^{3} / \mathrm{m}^{2}$ of water would be expected in a position directly over the verticai WP with the amount of water increasing with horizontal distance from the WP to a maximum of approximately $3.1 \mathrm{~m}^{3} / \mathrm{m}^{2}$ of water at the mid-pillas position. It would be expected that these differences would diminish as the boiling point isotherm continued to move out with increasing time until ultimately temperatures started to collapse. Only the relatively small volume of water which is transported directly above the WPs and the drifts will be available to migrate back to the area of the WPs. The larger volume of water transported to regions above the pillar would tend to flow vertically downward and only the small portion of this water that spread laterally would be able to come in contact with the WPs. 


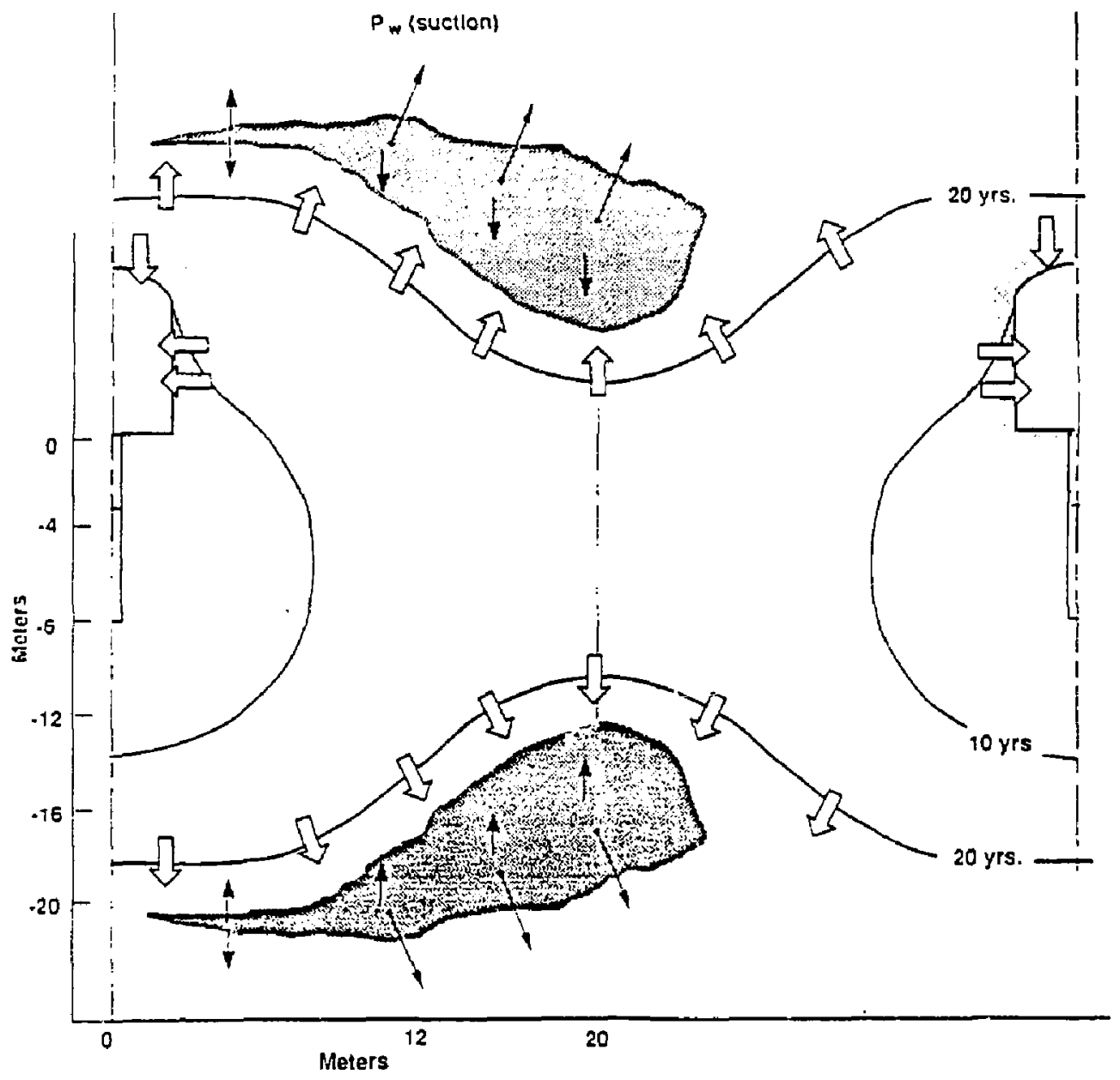

Figure 12c. Twenty years post-emplacement modified from Hertel and Petney (1989!

As can be observed on Fig. 13b, water vapor driven from the near-field environment of horizontally emplaced WPs during the first 10 years will largely condense in the rock-mass directly above or below the WPs. In contrast to the vertical emplacement case a relatively small volume of the moisture from the rock-mass immediately around the WPs will be ahle to escape into the drifts. Water that condenses will raise the saturation of the rock above the WPs and boiling point isotherm to a greater extent than in the mid-pillar region. Therefore, gravity flow will not be as effective in removing the build up of water from the WP environment as it would in the vertical case. Hertel and Petney analyses indicate that the boiling point isotherms from adjoining drifts do not coalesce until after 50 years (post-emplacement) but before 


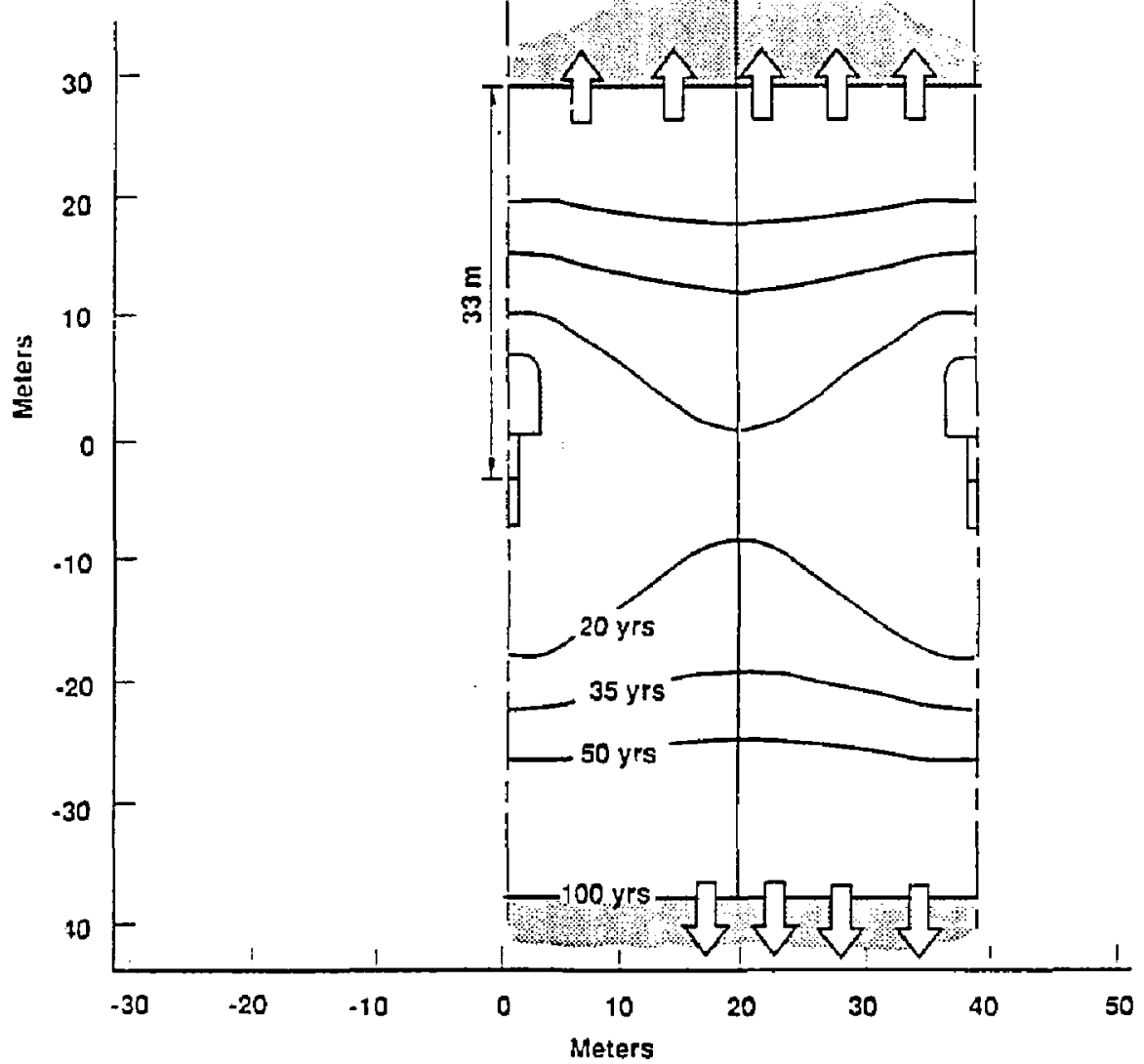

Figure 12d. One hundred years postemplacement modified from Hertel and Petney (1989).

100 years. Therefore, the downward migration of water can coninue for many years which may result in significant volumes of water removed by gravity flow even though the gravity flow mechanisms would be less effective than for the vertical emplacement case.

Because the isotherm shapes are similar from 10 years to almost 75 years, there will be no basic change in the hydrologic processes occurring during this time so those processors described for the fir st 10 years will continue except that the mois sure will continue to move further from the WPs. There wil! se a greater percentage of lateral movement icswards the pillar mid-plane because the isotherm's radius of cisvature is greater. However, this is not substantial anc the overall processes as described will remain the same.

After 100 years, the boiling point isotherms have coalesced (see Fig. 13c) and moisture/vapor movement will be nearly vertical in the regions directly above and below the WPs with a component towards the mid-pillar in the rock-mass beyond the ends of the emplacement holes. The same back-of-the envelope calculation of volume of water condensed during the first 100 years of drying was made for the horizontal emplacement case. In this analysis, the vilume of water in the rock above the WP elevation 


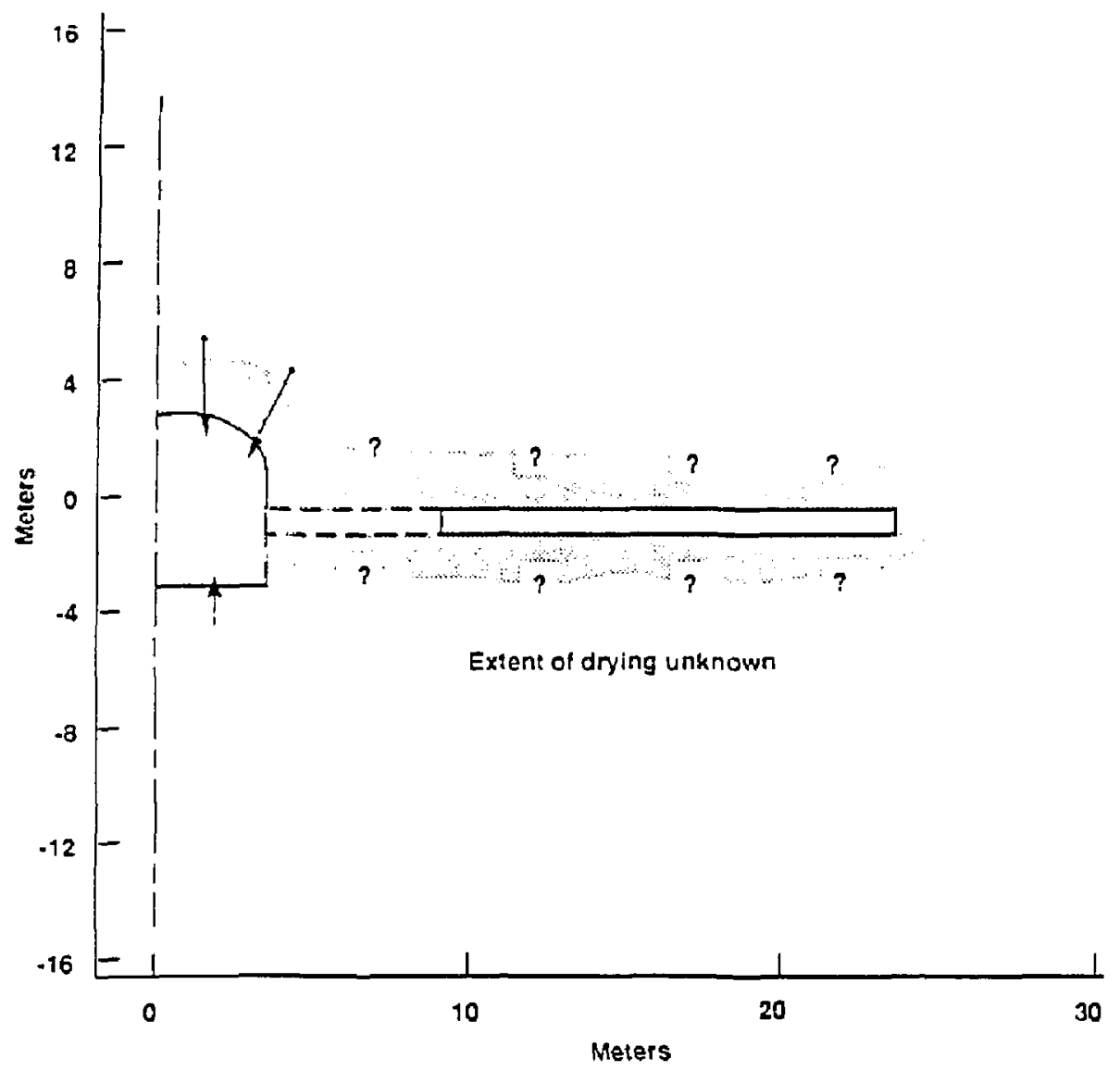

Figure 13a. Construction and preemplacement.

extending to the boiling point isotherm was calculated. The plot of this volume is shown on Fig. 14. As is apparer.t, the volume of water deposited in the rock-m.ass above the WPs varies from about $3.6 \mathrm{~m}^{3} / \mathrm{m}^{2}$ at the end of the WI closest to the drift decreasing to about $3.3 \mathrm{~m}^{3} / \mathrm{m}^{2}$ at the end of the WP deepest in the emplacement hole. Once again it is expected that the boiling point isotherms will continue to move away from the WPs until the cool down. As the isotherms move further from the WP horizon, the relative spatial differences in amount of water would diminish.

Thus, in the horizontal case a significant amount of water would be condensed in a position where it could potentially return to the WP emplacement holes.

\section{Effects of Drift Ventilation on Post-Emplacemer, Water Flow}

The amount of water driven off during heating and deposited above the waste packages is also in huenced by $h \mathrm{w} w$ much of the original water is removed by ventilation. Hopkins, et al. (1987) report that drift ventilation appreciably lowers drift wall saturation. They looked at the impact for $0.5 \mathrm{~mm} / \mathrm{yr}$ 


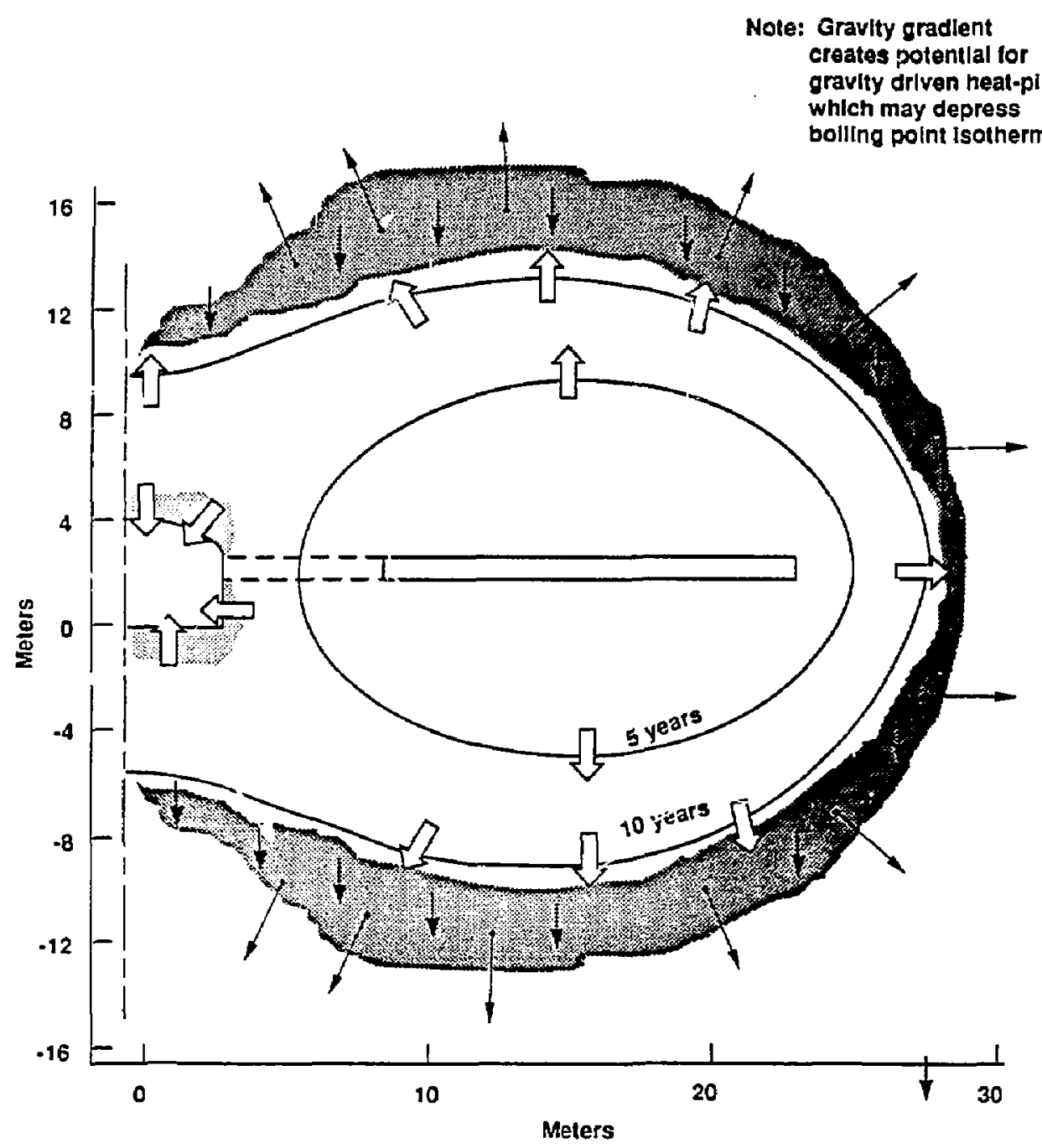

Figure 13b. Ten years post-emplacement modified from Hertel and P' iney (E989).

and $0.1 \mathrm{~mm} / \mathrm{yr}$ downward flux and vertical emplacement and found significant drying from the ventilation system, the effects of which would remain for about 225 or 380 years, respectively. These analyses did not consider the drying out that results from the thermal loading of the WPs, but can indicate the impact that ventilation has on the rock-mass. The impact of combined ventilation and thermal loading would be more dramatic than for ventilation alone since the saturation of the rock-mass surrounding the arifts will be lowered due to ventilation but the rock will not be entirely dried out. 


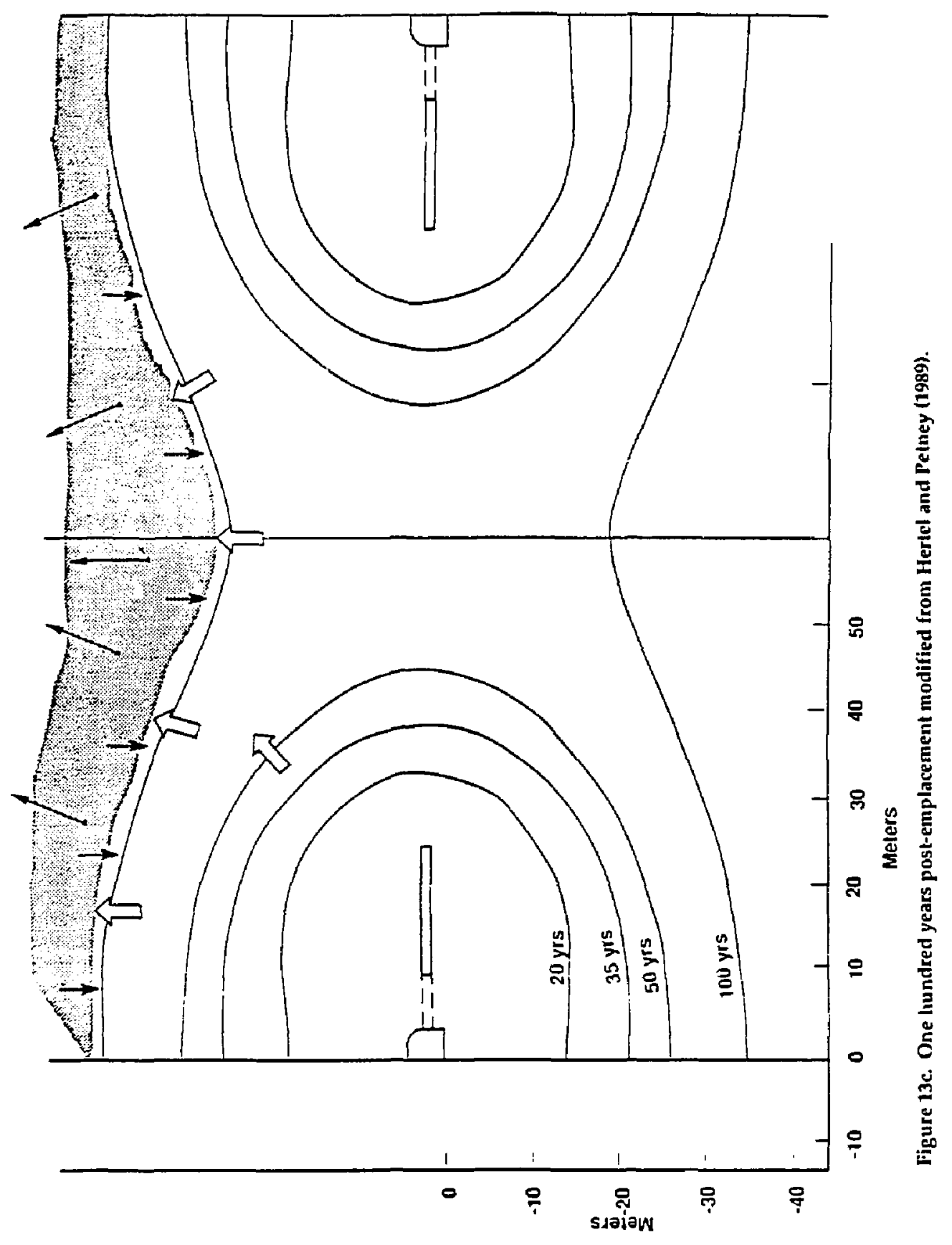




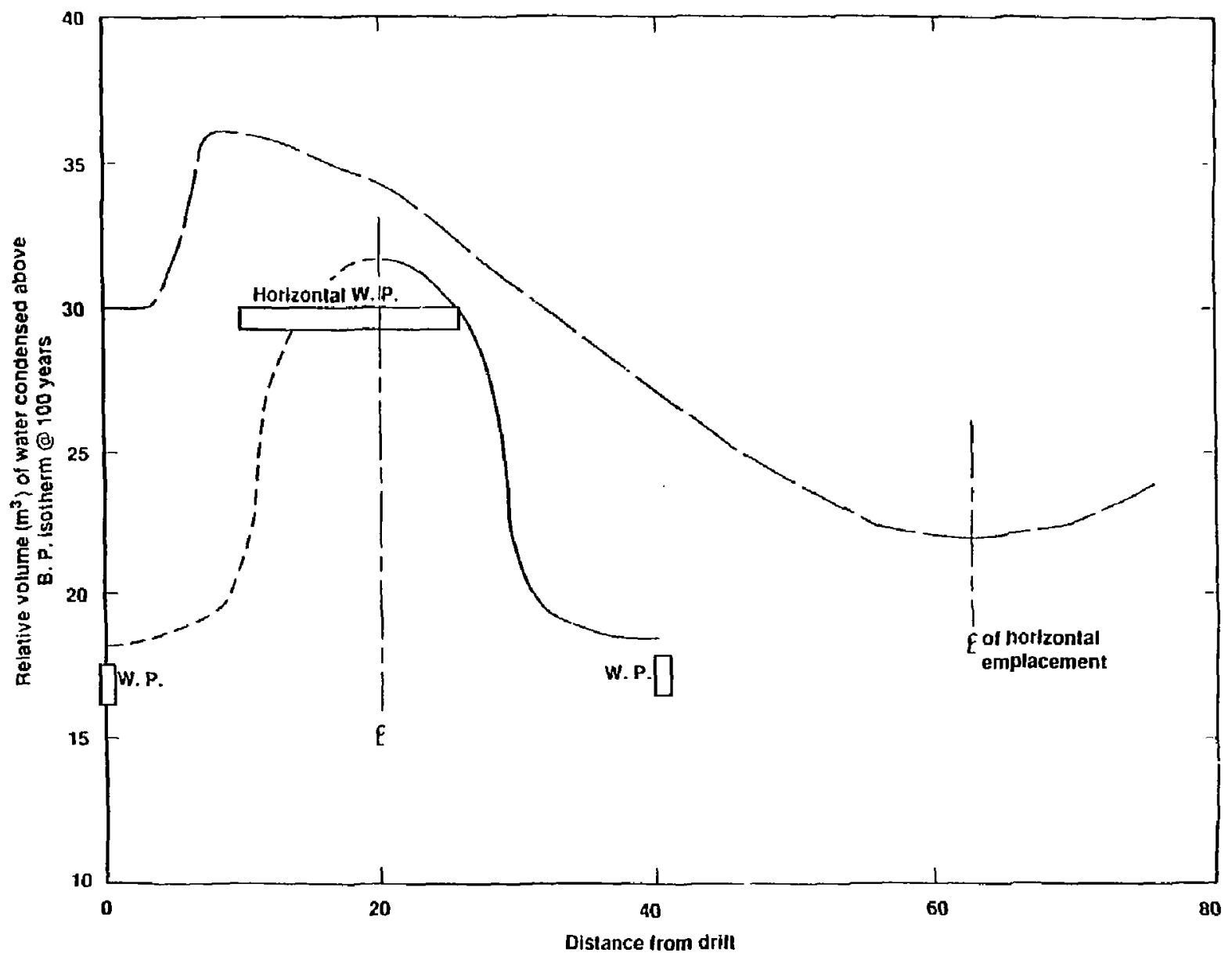

Figure 14. Volume of water condensed as a function of position. 
Hopkins, et al. show a generally symmetrical zone of decreased saturation (from almost $90 \%$ to less than $60 \%$ ) surrounding the drifts after 50 years of constant ventilation. This is indicated as the first stage of dry out shcwn on Figs. 12 and 13. During the first few years (possibly 40 years depending on repository operations) after waste emplacement, the drifts will remain open. During this early heating phase the moisture from the rock-mass surrounding the WP will be driven into drifts. As long as the vapor flow path to the drift is sufficiently short then a preferential pathway through the drift is significant. For this analysis, the author judged that preferential flow would occur through the drift for path lengths not exceeding 10 meters. Since it has been reported that air flow is fairly unrestricted through the mountain in response to barometric pressure changes, etc., it seems unlikely that the presence of the drifts will create significantly enhanced flow pathways for fracture flow path lengths to tie drifts greater than 10 meters. Therefore, the effects of ventilation alone are sketched conservatively on Figs. 12 and 13 to extend approximately $1-2 \mathrm{~m}$ and the flow during dryout was assumed to be preferentially into the drifts for 5-10 meters.

Since the rock-mass surrounding the drifts is directly above the waste in the vertical orientation, vertilation dryout will significantly enhince WP performance for this orientation. Firstly, the rock-mass above the WPs will be at lower saturations before waste emplacement so that less water will remain to be driven off after WP emplacement, and thus less water will condense and accumulate above the WPs. Secondly, during the emplacement period and the years after emplacement until drift backfilling or repository closure, much of the water vapor driven off by heat will be removed by the ventilation system unless panei drifts are sealed off after waste emplacement is completed. Thirdly, even if ventilation ceases after emplacement, much of the vapor will likely be condensed above the drift where it would be jr tbibed into rock matrix that had been dried by ventilation to a lowered state of saturation. This condensate would remain until sufficient water transport occurred under natural fux conditions to increase the saturation above pre-repository values. Fourthly, with drier rock the temperatures will be elevated over a greater rock-mass volume (less heat used in latent heat during vaporization) so that a larger volume will be dried out. Finally, as reported by Philjp (1987), under unsaturated conditions a drift may be designed to shed water off to the sides of the drift betore it could infil trate into the drift. This should potentially protect vertically emplaced WPs from water entry into boreholes. Therefore, the time at which water from the rock above the emplacement holes could enter vertical WP boreholes will be delayed relative to horizontal WP boreholes.

In summary, there are several differences in the impacts of construction and waste emplacement activities on the quantity of water that could contact WPs that depend on the emplacement orientation. For horizontal emplacement, the impact of the water from the dried-out rock-mass will be much different. Firstly, water may not be removed by ventilation from rock surrounding the wasie packages prior to emplacement (depending on hole length, standoff distance, and ventilation practices). Secondly, a significant portion of condensation of the water drive: 1 off after emplacement will occur in an area of rock above the WPs (see Fig. 13). Thirdly, after the rock-mass cools, the water above the WPs will be able either to flow directly down the fractures onto the containers or to saturate the rock near the WP to its original (or ne?" original) moisture conditions. If there is an overall downward flux and the saturation of the rock above the WP was increased by condensate, then an increased amount of the flux would be carried by the fractures thus increasing the rapidity with which water could potentially reach the WPs.

\section{Effect of Chemical Alterations in the Rock-Mass}

In addition to the removal of water from the dried-out zone, the impact of heat on water migrating downward (if any) under normal flux conditions and on chemical changes induced by the rock/water interactions at higher temperatures must also be considered. Chemical reactions between water and rock will likely be influenced by elevated temperatures. Also, the condensate chemistry will likely be different from the ambient pore water (lower in salts). During the period of high temperatures, this water may react with the minerals in the rock until an equilibrium condition is reached where the water may be similar to ambient water. When water, which might subsequently flow through the pores and fractures of the rock-mass under normal flux conditions, comes in contact with the condensate and with the salts 
left behind when the water vaporized, it will likely interact with the condensate and salts to corne to a new equubrium condition. The effects of these interactions cannot be assessed at this time.

\section{Fracture Healing Induced Modifications of Water Flow}

$\mathrm{Li}$ : and Daily (1984 and 1988) and Daily, et al. (1987) have reported that heat-induced drying results in possible fracture healing. If the healing is total and permanent, then the impact would be the same for horizontal or vertical orientations. However, if the healing is reversible by subsequent leaching, then the vertical orientation would produce the more stable healing since only a small portion of the percolating water would contact the healing materials.

\section{Waste Package Issue Resolution Strategy}

An important hydrologic consideration is the extent to which the WP lssue Resolution Strategy (IRS) will be satisfied. Water migrating into the dried-out zone will lower the temperature more rapidly than will conduction alone. In the vertical emplacement mode, a large percentage of the water driven off during the first 20 years of heating will likely- flow to an elevation below the WPs (see Fig. 12) or be removed by ventilation (depending on ventilation rates and drift closure). During the early heating period, this water will not flow back into the dried-out zone and therefore will not impact the rock temperature immediately around the borehole (see Figs. 12b and 12c).

Furthermore abcut $5 \%$ of the moisture originally contained within the rock volume that would bs heated to the boiling point during the first 20 years after waste emplacement would have been removed either by the mining process itsel (the mositure removed with the rock) or by the ventilation system.

For horizontal emplacement, the moisture removed during excavation and by ventilation would not influence the temperatiure distribution signnificantly since much less than $5 \%$ of the moisture contained within the volume of rock heated to the boiling point during the first 20 years after emplacement would be removed by either mining or ventilation. Further, a heat pipe might occur where water would first be vaporized and travel upward until it condensed. The water might then collect in that portion of the rock until sufficient volume of water accumulated so that gravity would excecd matric potential. Once water flows back into the region of rock where temperatures were above the boiling point it would then revaporize. The latent heat to revaporize this water would directly impact the volume of rock that could be dried out as well as the temperature distributions and time history of temperatures. This mechanism might also influence the shape of the isotherm and how rapidly it extended away from the WPs but would have minor infiuence on the total amount of water that accumulated above the WPs. These heat pipe effects could be significant since once sufficient saturation is built up flow can occur both in the matrix due to saturation gradients as well as in the fractures. If a heat pipe is established, it could adversely impact the WP performance strategy which is based on limiting the amount of liquid water contacting WI's.

In the case of horizontal emplacement, the potential for heat pipe effects will be concentrated above the WPs during the first 50-75 years since that is where the major volumes of moisture condensation would occur (see Fig. 13). In the case of vertical emplacement, the isotherm becomes essentially horizontal between $35-50$ years, but the location most likely to develop heat pipe effects would be above the mic-pillar where the largest volume of condensate would accumulate. This may influence the shape of the boiling point isotherm and thus influence where moisture accumutation will most likely occur.

The above discussion was based on the work of Hertel and Petney (1989), which did not account for fracture vs matrix flow. However, until detailed hydrothermal analyses are completed it appears that there will be significant differences in the potential for heat pipes to develop for the h.orizontal and vertical orientations. 


\section{Effect of Backfilling of Drifts on Waste Package Performance}

Backfilling of drifts at time of closure may also have different impacts on the WP performance for vertical versus horizontal emplacement. The backfill material will most likely be crushed tuff excavated from the repository drifts. This material may be stored on the surface (particularly for early drifts) or may be moved from drifts being excavated into drifts where waste emplacement had been completed. (It is not clear at this time if backfilling of drifts during the retrieval period will be allowed.) The storage (particularly on the surface) and handling of muck will decrease the degree of saturation of this material. The backfill will then act as a gap-graded porous medium (no continuous fractures will remain after backfilling) with lower saturation than the rock matrix. Until the saturation of the backfill increases to that of the surrounding rock, it will act as a sink for moisture. Whether this backfill material will act as a wick to moisture from rock-mass above the drift or as a capillary barrier to flow will depend largely on the degree of saturation of the backfill material, on the relative pore size of the backfill, and on the amount of contact between the backfill and the crown of the drift. However, once cool down has occurred, the backfill will absorb moisture and hold it until the degree of saturation is at least es great as that of the underlying rock-mass. The backfill will also alter fracture flow above the drifts to porous media flow through the backfill, thus dispersing it over a wider area. Thus only a fraction of the w.1ter flowing in fractures above the drifts will be able to flow through drift backfill, and rez:ier the si me fractures below the drifts. The remander of the water from above the drifts, that is not held in the backfill, is not diverted down drift along the contacts between rock and backfill, or does not re-enter fractures, will be imbibed from backfill into the rock-mass. Additionally, because of permeability contrasts between backfill materials and drift surfaces (and possibly even anisotropic permeability of backfill materials resulting from backfil' ;rocedures). it is possible that sub-horizontal permeabilities will be greater than vertical permeabilitie ..irough the rock/drift segments. This would divert water down drift along contacts between backfill and rock. All oi these processes would act as a partial barrier to flow into WP boreholes.

\section{Mechanical Stability of Emplacement Boreholes}

A performance issue for the WP not directly related to the hydrology, and therefore not discussed at length in this paper, nevertheless can impact the hydrologic aspects and should be ecognized. This has to do with the stability of toreholes. Unless the strength of the intact rock is exceeded or the rock-mass creeps, any rock entiring the boreholes will be a result of block motions along fractures, rather than failures of the rock. Blocks entering the bore'inles can serve as a pathway for water to wick onto the waste packages. Since the fractures are predominately vertical, the dimensions of unstable blocks are potentially much larger for vertical-emplacement boreholes than for horizontal boreholes. Blocks larger than the borehole could not move into the boreholes. Since blocks will be smaller for horizontal boreholes, these boreholes are potentially less stable. Therefore, the vertical-emplacement boreholes should be more stable than horizontal-emplacement boreholes. Since borehole stability (assuning no liner is present) will be a function of orientation of boreholes relative to fractures (among other parameters), this needs to be considered in the decision of emplacement orientation.

\section{Waste Package Emplacement Design Flexibility}

A final point to be made is the potential for designing the boreholes and repository facilities to help ensure WP performance. In the case of vertical emplacement, three fairly easily achieved design features can be used to ensure that the WTs remain dry for as long as possible. The first is to drill the boreholes deeper than required for waste emplacement to provide a sump for water to flow into. Because the sump provides increased vertical dimension, borehole drainage through fractures as well as imbiitition into rock would be increased, thus minimizing the bathtub effect. Second, a capillary barrier between the WP container and the rock-mass could be ensured by either hanging the WP in the hole or, if the WP was supported by the bottom of the hole, by placing a gravel or similar non-porous aggregate backfill material 
in the sump portion of the borehole. The inal material specification could be determined to balance between prevention of inflow into the borehole by wicking (non-porous aggregate has no matric potential) and providing material to wick away any moisture from the WP which may collect on the bottom contact of the WP. Finally, a seal plug or cap could be installed above the borehole to intercept any water flowing vertically downward through the drift above the $W_{1}$ ' borehole and deflect that water to the sides of the drift where it would not be in a direct flow path in the borehole. These designs are illustrated in Fig. 15. Other than inclining the boreholes to provide drainage and instaling liners, no similar design features could be easily applied to the horizontal emplacement orientation. An inclined borehole should allow water to flow towards the collar and escape into the drift. It is not clear whether in so flowing :tat water would contact the WPs or whether the water vapor would collect on surfaces and drio onto containers. The issue of liner lifetime and whether they could survive 10,000 yrs to protect WPs during $_{15}$ the time frames that they will be required to function is also not known. Because of these unknowns, it does not apprar that these design options are as reliable as are the ones for vertical orientation.

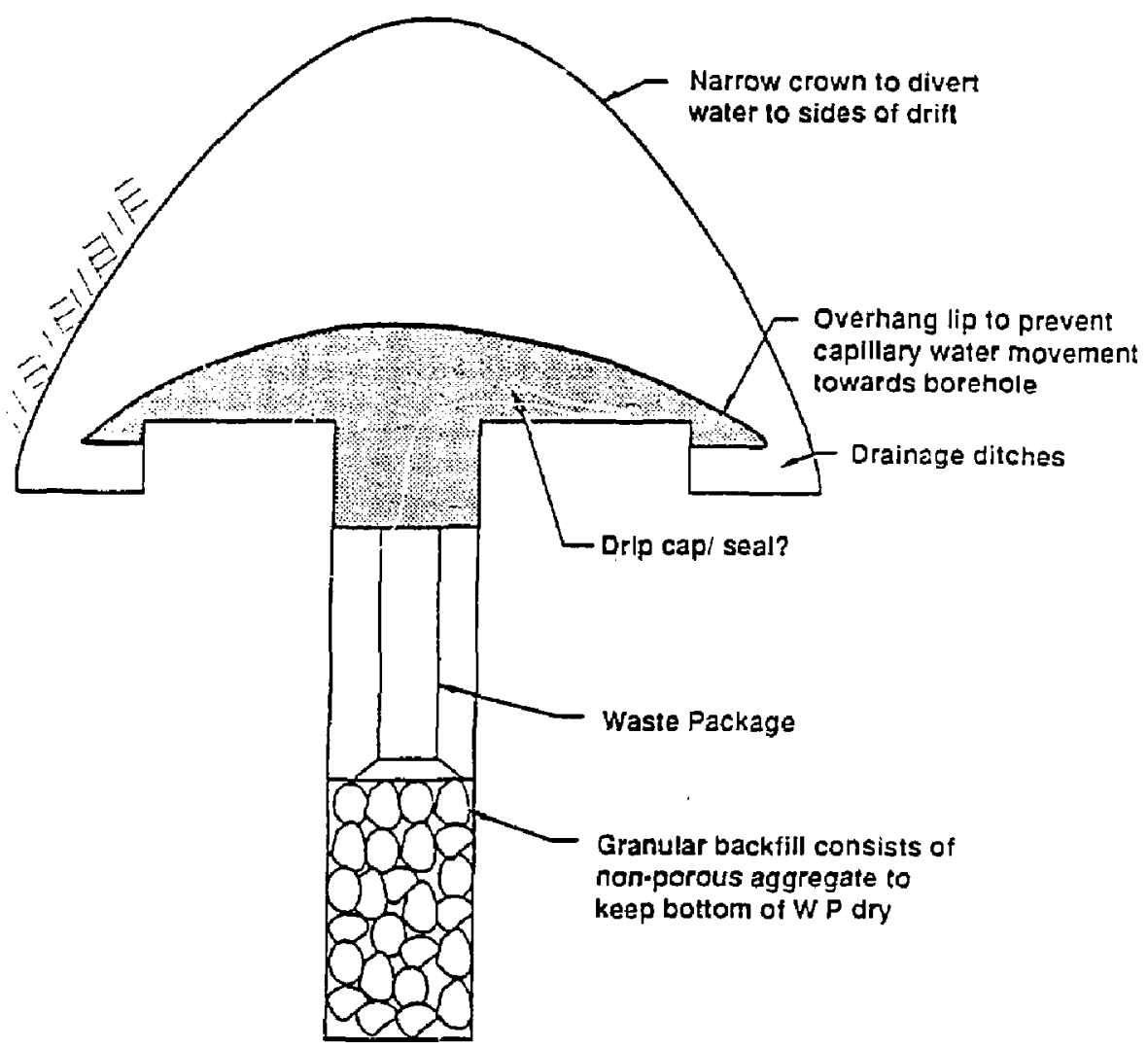

Figure 15. Design aspects of vertical emplacement orientation to ameliorate water contact with WP. 


\section{CONCLUSIONS AND RECOMMENDATIONS}

Several Waste Package Performance issues related to the hydrologic or waste package environment have been identified as being influenced by the emplacement orientation. From a Waste Package Performance standpoint, the vertical orientation is preferable. The issues and summary of findings follow:

- The considerably larger aumber of fractures intersected by horizontal boreholes in comparison with vertical boreholes will potentially allow greater volumes of fracture flow water resulting from very heavy recharge events to enter horizontal boreholes. In addition, the orientation of the intersection between vertical fractures and horizontal boreholes is more conducive to water entry into these boreholes than is the case for vertical boreholes. This latter factor is even more pronounced in unsaturated condstions where there is not a significant pressure head, only gravity or elevation head.

- Water is more likely to fall directly onto WPs in horizontal boreholes than in vertical boreholes. In horizontal holes, a prtion of the borehole wall is nearly horizontal so water can collect unti] it drips into the hole. In vertical boreholes, water collecting on the wall surface would run down the borehole wall to the bottom of the hole.

- The potential for salts deposited at the time of water vaporization to influence WP performance is greatest in horizontal holes. Two factors must be considered. First, the groundwater at Yucca Mountain is expected to be very dilute and therefore, the amount of salt deposited upon vaporization will be very small for a single cycle of vaporization. The potential for refluxing of water or entry of additional water to continue the build up of $s e^{\prime} ! s$ is greater in the horizontal orientation. Secondly, the potential for water that leaches the salts to then contact the WPs is greater in the case of the horizontal WP orientation. Both of these factors may be of less concern if a liner can be designed that will servive for a 10,000 year period when WPs have performance objectives.

- There is greater potential in horizontal boreholes for increased fracture opening after cooldown and. therefore, for flow through those fractures into the WP boreholes. This is because, in the case of horizontal waste emplacement, there is greater shear formation during the heating and subsequent cooling sycle which enhances the permeability of the fracture system. In the vertical emplacement mode, deformations will be predominantly normal (perpendicular) to the vertical fractures. In the horizontal orientation, deformations of the predominantly vertical fracture system will have a significant component of shear.

- Water driven oif as vapor will more likely return to the horizontal WPs than to the vertical WPs. In the horizontal case, a significant portion of the condensate will collect directly above the WPs. In the vertical orientacion, most of the condensate will collect laterally away from the WPs.

- Ventilation of the drifts may remove a significant amount of moisture from the rock-mass surrounaing the drifts. In the vertical orientation, the dried-jut zone will be directly above the WPs so that less water will be available to enter the WP boreholes after cooldown. In the horizontal emplacement, the ventilation- $d$ ried zone will not be principally above the WPs. In the vertical case, the ventilation system will also remove a larger percentage of water during the early portions of ti.e thermal cycie (after emplacement but before r.Josure), since the water vapor will tend to rise (density difference) and can easily enter the drifts by traveling upward in the vertical fracture system. In the horizontal case, vapor would rise above the drifts whe- it would not be readily removed. Ventilation 
influences not only the amount of water potentially enteriris WP boreholes, or more precisely how soon water can begin to enter the boreholes, but alsc will influence rock-mass temprature distribution. With less water to vaporize, more of the heat generated by the waste will be adds-d to the rock-mass.

- Drift backfill will likely be at lower saturation than rock matrix. This would delay the ti:ne when water flowing through the matrix could enter the vertical boreholes, and will tend to divert a significant portion of any water that flows through the fractures above the drift. The result would be that much of the water from fractures above the drift would not fow into the fractures below the drift that would provide pathways into the boreholes, but rather would spread out in the backfill and the rock matrix.

- Borehole stability will likely be enhanced in the vertical case in comparison with the horizontal emplacement case. This will affect not only loading on WPs, but also the potential for wicking of water in to the WPs.

- Engineering design to prevent adverse effects of water on the WPs can be more readily achieved for vertical emplacement than for horizontal emplacement.

\section{ACKNOWLEDGMENTS}

The author gratefully acknowledges the review input of T. A. Buscheck, W. G. Glassley, E. S. Hertel, A. Thompson, A.J. Wijesinghe, and J. L. Yow, Jr.

Prepared by Yucca Mountain Site Characterization Project (YMP) participants as part of the Civilian Radioactive Waste Management Program. The YMP is managed by the Yucca Mountain Site Characterization Project Office of the U.S. Department of Energy, Las Vegas, Neyada.

\section{BIBLIOGRAPHY}

Bandis, S., A. C. Lumsden, and N. R. Barton, 1983. "Fundamentals of rock joint deformation," International Tournal of Rock Mechanics, Mining Sciences and Geomechanics Abstracts, Vol. 20, Pp. 249-268. NNA.890928.0106

Barton, N. R., S. Bandis, and K. Bakhtar, 1985. "Strength, deformation and conductivity coupling of rock joints," Intemationa] Journal of Rock Mechanics, Mining Sciences and Geomechanics Abstracts, Vol. 22, No. 3, pp. 121-140. NNA.891101.0025

Bawden, W. F., J. H. Curran and J. C. Roegiers, 1980. "Importance of joint behavior on potential water inflow into underground structures-an analytical approach," Underground Rock Engineering, 13th Rock Mechanirs Symposium, The Canadian !rstitute of Mining and Metallurgy, CIM Special Volume 22, Montreal, Quebec, pp. 211-218. SRX.830622.0017

Blejwas, T. J., personal communication during NNWSI meetings, November-December 1987.

Daily, W.D., W. Lin, and T. Buscheck, 1987. "Hydrological Properties of Topopah Spring Tuft: Laboratory Measurements," Lournal of Geophysical Research, Vol. 92, No. 88, pp. 7454-7864. NNA.870713.0080

"Exploratory Shaft Test Plan," Rev. 2 draft, December 1987, DOE NVO-244. NNA.871229.0018

Hertel, E. S., and S. V. Petney, 1989. "Location of the Boiling Isotherm and Predictions of the Water Influx into a Typical Waste Emplacement Drift," SLTR 89-4001, Sandia National Laboratories.

Hopkins, P. L., R. R. Eaton, and S. Sinnock, 1987. "Effect of Drift Ventilation on Repository Hydrology and Resulting Solute Transport Implications," SAND86-1571, Sandia National Laboratories. HQS.880517.2712

Lin, W., and W. D. Daily, 1988. "Hydrological Properties of Topopah Spring Tuff under a Thermal Gradient, Laboratory Results," UCRL-96926, Lawrence Livermore National Laboratory, Livermore, CA. NN1.8810270006

Lin, W., and W. D. Daily, 1984. "Transport Properties of Topopah Spring Tuff," UCRL-53602, Lawrence Livermore National Laboratory, Livermori, CA. HOS.880517.2486 
McCright, R.D., W. G. Halsey, and R. A. Van Konynenburg, 1987. "Progress Report on the Results of Testing Advanced Conceptual Design Metal Barrier Materials under Relevant Environmenral Conditions for a Tuff Repository," UCID-21044, Lawrence Livermore National Laboratory, Livermore, CA. NNA.871214.0013

Montazer, P., and W. E. Wilson, 1984. "Conceptual Hydrologic Model of Flow in the Unsaturated Zone," Yucca Mountain, Nevada: USGS-OFR-84-4345, U.S. Geological Survey Denver, CO. NNA.870519.0109

Nitao, J. J., 1988. "Numerical Modeling of the Thermal and Hydrological Environment around a Nuclear Waste Package Using the Equivalent Continuum Approximation: Horizontal Emplacement," UCID21444, Lawrence Livermore National Laboratory, Livermore, CA. NNA-890317.0021

Philip, J. R., 1987. "An Analog for Infiltration and Unsaturated Seepage," EOS March 17, 1987 Americari Geophysical Union, Washington, DC, pp. 153-154. HOX.880818.0012

Scott, R. B., and M. Castellanos, 1984. "Stratigraphic and Structural Relations of Volcanic Rocks in Drill Holes," USW GU-3 and USW G-3, Yucca Mountain, Nye County, NV, USCS-OFR-84-491, ㄴ.S. Geological Survey Denver, CO. NNA.870519.0095

DOE, 1988. Site Characterization Plan: íucca Mountain Site. Nevada Research and Develnpment Area, Nevada U.S. Department of Energy, Office of Civilian Radioactive Waste Management, Washington, D.C., DOE/RW-0199.

St. John, C. M., 1987. "Reference Thermal ard Thermal/Mechanical Analyses of Drifts for Vertical and Horizontal Emplacemer: of Nuclear Waste in a Rerusitory in Tuff," SAND86-7005, Sandia National Laboratory, Livermore, CA. NNA.870318.0306

Wilder. D. G. , 1987. "Influence of stress-induced deformations on observed water flow in fractures of the Climax granitic Stock," Rock Mechanics: Proceedings of the 28th U.S. Symposium. A. A. Balkema, pp. 491-499. HOX.880425.0031

Yow, J. L., Jr., and D. G. Wilder, 1984. "Planning Exploratory Drilling: The Effect of Blind Zones and Level of Logging Effort," Proceedings U.S. Symposium on Rock Mechanics, pp. 807-812, Texas A and M University, College Station, TX, and the Association of Engineering Geologists, Knoxville, TN. NNA.891109.0041

Yow, J. L., Jr. 1987. "Blind Zones in Acquisition of Discontinuity Orientation Data," Intermational Yournal of Rock Mechanics, Mining Sciences, and Geomechanics Abstracts, Vol. 24, No. 5 pp. 317-318. NNA.891101.0026 
The following number is for Office of Civilian Radioactive Waste Management Records Management purposes only and should not be used when ordes ing this document:

Accession Number: NNA.910520.019r 